\title{
MOVIMIENTO EN DEFENSA DEL LAGO DE LA COCHA, PASTO, NARIÑO, COLOMBIA \\ $(1993-2001)^{1}$
}

\author{
ARIEL EDMUNDO TARAZONA PEDRAZA ${ }^{2}$ \\ aetarazonap@gmail.com
}

Manizales, 2010-04-28 (Rev. 2010-05-24).

\section{RESUMEN}

Este movimiento ambientalista es una resistencia local que se gesta en la última década del siglo XX en Pasto (Nariño, Colombia) frente al avance del Proyecto Multipropósito Guamués -PMG- que impactaría el Lago de la Cocha.

EI PMG había sido proyectado bajo la alianza de la sociedad económica y la sociedad política regional, que bajo una concepción desarrollista, planeaban tomar aguas del Lago para consumo humano, regadío y generación de electricidad con fines comerciales.

Desde otra racionalidad la sociedad civil, entendida por el movimiento ambientalista que se gestó en reacción al PMG, tenía otra visión socio-ambiental del cuidado del Lago. Estas dos visiones antagónicas originan un conflicto ambiental.

El movimiento ambientalista generó todo un trabajo en red (campesinos del Lago, ONG locales regionales e internacionales, grupos de expertos, universidades e instituciones gubernamentales) obteniendo un alto grado de opinión pública en defensa del Lago de la Cocha.

La influencia ejercida desde la red consiguió que el Lago fuera declarado humedal Ramsar en el año 2000, logrando la negación de la licencia ambiental al PMG por parte del entonces Ministerio del Medio Ambiente.

\section{PALABRAS CLAVE:}

Movimientos sociales contemporáneos, movimientos ambientalistas en Colombia, conflicto socioambientales, política cultura, sociología de la cultura.

\section{MOVEMENT IN DEFENSE OF LA COCHA LAKE, PASTO, NARIÑO, COLOMBIA \\ (1993-2001)}

\section{ABSTRACT}

This environmental movement acts as a local resistance that originated in the last decade of the 20th century in Pasto (Nariño, Colombia) against the execution of the Guamés Multipurpose Project -GMP- that would cause great environmental impact on La Cocha lake. 
The GMP had been created by the partnership between the economic and the political regional societies that, based on developmentalist ideas, were planning to take water from the lake to be used for human consumption, soil irrigation and electricity production with commercial purposes.

The civilians who founded the movement against the GMP had a different vision on how to protect the lake based on social and environmental theories. These two different points of view created an environmental conflict.

This environmental movement generated a wide network between farm workers from the area, regional and international NGO's, academic experts, universities and governmental institutions, obtaining a great deal of interest from the public opinion.

Under the strong influence of this network the lake was declared as the Ramsar Wetland in 2000, and the former Department of the Environment denied the environmental license requested by the GMP.

Key words: Contemporary social movements, environmental movements in Colombia, social and environmental conflict, cultural politics, sociology of culture.

\section{INTRODUCCIÓN}

El presente artículo nos ilustra los orígenes y el proceso de movilización en torno a la defensa y protección del ecosistema del Lago de la Cocha, localizado en el sur de Colombia, departamento de Nariño, municipio de San Juan Pasto, frente al avance del Proyecto Multipropósito Guamués -PMG-.

El proyecto Multipropósito Guamués I [...] planeado para generar beneficios energéticos, de acueducto y riego. El proyecto incluye la construcción de una central hidroeléctrica con una capacidad instalada entre 367 y 482 MW, dependiendo del caudal ecológico que se preserve en el cauce del río Guamués; además permite atender, a partir del año 2025, los incrementos de agua potable de la ciudad de Pasto y sus alrededores, y también, prevé el suministro de agua para riego de una extensión de 4208 hectáreas en la zona aledaña a dicha ciudad. (Price Waterhouse Coopers, 1996, p. 200)

La movilización fue propiciada hacia 1997 por la unión de Organizaciones no Gubernamentales Ambientalistas -ONGA- locales especialmente de la Asociación para el Desarrollo Campesino -ADC- y la fundación Ecovida, la Universidad de Nariño -UDENAR- en compañía de campesinos y pobladores de la Cocha, con la asesoría y el acompañamiento de organizaciones regionales como Asdes (Cali), Parques Nacionales e internacionales como el Fondo Mundial para la Naturaleza -WWF-. 


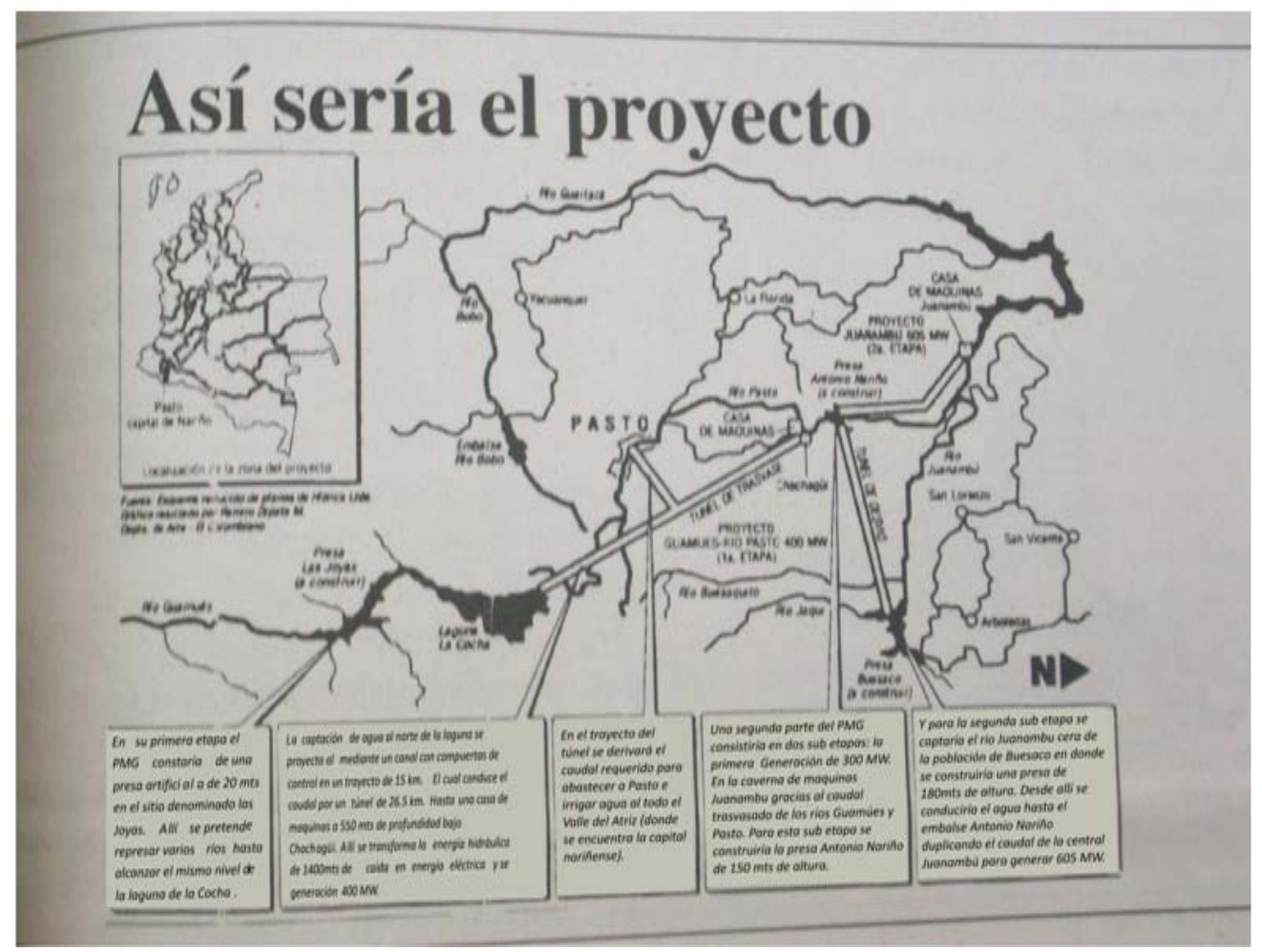

Figura 1. Etapas del Proyecto Multipropósito Guamués -PMG-. (Diario del Sur, Pasto, 19 de junio de 1996, p. 3b).

Este movimiento ambientalista se oponía a la construcción de una represa que alteraría el equilibrio normal del Lago de la Cocha, y defendía como ecosistema principal los páramos azonales o más bajos del mundo que se verían destruidos con el represamiento de agua adicional al Lago de la Cocha en su estado "natural". Octavio Duque López ${ }^{3}$ en sus escritos en defensa del Lago de la Cocha se refiere así a estos ecosistemas:

La Cocha presenta un evento casi único en el planeta, cuando alrededor de quince mil hectáreas que forman los valles de los ríos Guamués, Estero y Esterillo y Loriana a $2760 \mathrm{msnm}$, se convierten en los páramos más bajos del mundo, mostrando un paisaje de bosques sobre ellos, e influyendo definitivamente sobre el comportamiento del río Guamués en todo su cauce hasta la desembocadura en el río Putumayo. (Diario del Sur, 4 de marzo de 1996, p. 12a)

Para lograr sus objetivos, el movimiento optó por acceder a la influencia que ejerce el conocimiento experto en la opinión pública, de esta manera logró persuadir a instituciones locales, regionales, nacionales e internacionales en decretar el Lago de la Cocha humedal Ramsar ${ }^{4}$, esto trajo conexo la negación de la licencia al PMG por parte del entonces Ministerio del Medio Ambiente MMA-.

Este proceso, puede ser entendido en términos de la influencia. "La influencia la introdujo Talcott Parsons como una forma simbólicamente generalizada de comunicación que gobierna las interacciones en virtud de la convicción razonada o de la pura sugestión retórica" (Habermas, 1998, p. 443). Es decir, tanto la 
convicción razonada y la sugestión retórica fueron dos de los mecanismos utilizados por el movimiento en defensa de la Cocha frente al PMG.

La exposición presenta el siguiente orden: primero se señalarán los orígenes de dos ONGA locales de Pasto que permitieron la movilización de resistencia. En segunda instancia se mostrarán las estrategias de resistencia pacífica del Movimiento a partir de las redes generadas en torno a la UDENAR, la WWF, Parques Nacionales, para decretar el Lago de la Cocha humedal Ramsar y detener el PMG. Por último se ilustrará la influencia del Movimiento en Defensa de la Cocha sobre la sociedad política local, regional y nacional para incidir en la decisión del no licenciamiento ambiental al PMG.

\section{Ecovida, cadena de movimientos}

La Fundación Ecovida, Organización no Gubernamental de carácter ambientalista -ONGA- de Pasto con aproximadamente 24 años de existencia, fue una de las dinamizadoras de la resistencia local al PMG y su origen está asociado a varias circunstancias como la creación de los grupos ecológicos en la Universidad de Nariño -UDENAR-, el contacto con miembros del movimiento ambientalista nacional de la época y el enlace con movimientos de izquierda locales. Jairo Hernán Álvarez (1997) ha narrado la emergencia de los movimientos ambientalistas en Colombia, comparte estas características como puntos de partida:

Inicios que se basaban fundamentalmente en la creación de grupos ecológicos [...] muchos de ellos surgieron por intereses particulares y en especial alrededor del trabajo en las universidades [...] pues muchos de ellos venían de algunas experiencias de izquierda, otros se encontraban dentro de los movimientos estudiantiles y otros lo realizaban por el compromiso científico del conocimiento. (p. 28)

Los grupos ecológicos en la UDENAR se vieron motivados por el interés de hacer ciencia y a la vez, conciencia ambiental, como lo comenta la profesora Leonor Martínez:

Nosotros teníamos un grupo ecológico con Alirio Narváez, un profesor investigador, y él estudiaba mucho el río Pasto y la Cocha. Entonces, en la Asociación de Ciencias Biológicas, él era el fuerte en este tema, nosotros empezamos como por allí, la cuestión ecológica y sobre todo él decía, no, para el 2000 va a haber dificultades de abastecimiento de agua, trabajen desde ahora, jóvenes, investiguen, entonces nosotros empezamos con él. (Entrevista con Leonor Martínez, 2008)

Hay una relación estrecha entre Ecovida de Pasto con Gonzalo Palomino de la Universidad del Tolima y el periódico SOS al igual que con la Fundación Grupos Ecológicos del Risaralda -FUNDAGER-, y los debates que se mantenían en el plano nacional del movimiento ambientalista en construcción de la época, al respecto:

Hubo un Congreso [...] entonces habían funcionarios y los ambientalistas. Entonces, en ese momento nos partimos, un grupo con Gonzalo Palomino y otro grupo desde la institucionalidad. Entonces a raíz de eso, pues nos hicimos amigos del loco Gonzalo y él como tenía el SOS [...] y nos mandaba pues a todos a culturar por Colombia, entonces ese fue como nuestro nacimiento, y después a raíz de esa relación nos hicimos amigos de los de FUNDAGER y 
asistimos a ECOGENTE un Congreso que hubo, yo fui allá, y estuve con ellos y, me acuerdo tanto, estuvo el Maestro Ángel Maya, y nos siguieron invitando así a congresos nacionales. (Entrevista con Leonor Martínez, 2008)

El papel que jugó el periódico SOS en la inspiración de líderes locales de los movimientos ambientales en Colombia es ratificado por el propio Gonzalo Palomino (1997) quien asevera:

Han ocurrido cosas que realmente me llenan de mucha satisfacción y es que uno se encuentra a una gente que dice que le deben toda su motivación ecológica al SOS [...] Parece que cumplió, de verdad, un buen papel en el proceso de movimiento ecologista nacional. (p. 116)

Hay otro profesional connotado de la ONGA Ecovida, es Luís Eduardo Sánchez quien mantenía una columna en el Diario del Sur titulada Píldoras Ambientales. En general, el perfil de los actores movilizados de la ONGA Ecovida son profesionales con diferentes roles en la sociedad, por ejemplo: Leonor Martínez era profesora, madre, esposa y líder activista.

Los actores conflictivos no limitan su figura social a las pugnas en las que participan. No importa que esto se mida respecto al tiempo de vida o respecto a la multiplicidad de papeles desarrollados en distintos subsistemas, el compromiso de un conflicto antagónico no cubre toda la gama de posibilidades de acción de un actor dado. Ningún actor está definido única ni principalmente por su implicación en un movimiento de carácter antagónico (y de aquí la inutilidad de comparar a los actores de los movimientos contemporáneos con las características de la clase obrera). (Melucci, 2002, p. 79)

La formación en ciencias naturales y la sensibilidad por las temáticas cívicas le permiten a Leonor Martínez la incursión en los movimientos de izquierda, con su participación en el Comité Cívico y Popular de Pasto y en el Movimiento Popular de los Inconformes. El contacto con estos líderes permite a la ONGA Ecovida generar lazos de apoyo y solidaridad en los movimientos ("política de identidad") que serán vitales en la primera batalla pública contra las siembras de especies exóticas (eucalipto y pino), un proyecto de Cartón de Colombia para Pasto. Para esta acción, Ecovida recurre por medio de la "política de influencia" al Concejo local de Pasto donde se hace una serie de debates que son apoyados por el conocimiento experto de la Universidad Nacional. Como anotó Habermas (1998), tanto el influjo político como el conocimiento experto son generadores de influencia en el espacio de la opinión pública y en este último es donde se debaten los movimientos sociales.

Se deja entrever la pertenencia de los movilizados a diferentes organizaciones, colectivos y movimientos, confirmándose que en "las redes de reclutamiento, ningún proceso de movilización comienza en el vacío [...] quienes se movilizan nunca son individuos aislados y desarraigados" (Melucci, 2002, p. 62). Este proceso de movilización de Ecovida no es en el vacío, corrobora cómo el discurso ecológico al colonizar movimientos de izquierda, también recibe sus procesos de militancia, lo cual ya ha sido reseñado por Álvarez (1997) en la emergencia de los movimientos ambientalistas colombianos, quien enuncia:

[...] eso posibilitó que personas venidas de diferentes experiencias políticas, comunitarias de izquierda, de derechos humanos de lo jurídico y de género, se acercaran al tema, así aparecieron muchos de los que hoy en día están, enriqueciendo y aportando nuevos elementos de análisis. (p. 32) 
La emergencia de la ONGA Ecovida, está asociada al liderazgo de su mentora Leonor Martínez y principalmente a tres fuerzas: los grupos ecológicos de la UDENAR, el contacto con procesos del movimiento nacional en construcción y los movimientos de izquierda de Pasto. Por lo tanto, el origen de Ecovida, se gesta en redes de movimientos, en cadenas de movimientos. A continuación se conocerá sobre el origen de la Asociación para el Desarrollo Campesino -ADC-, ONGA que participó activamente en la defensa del Lago de la Cocha.

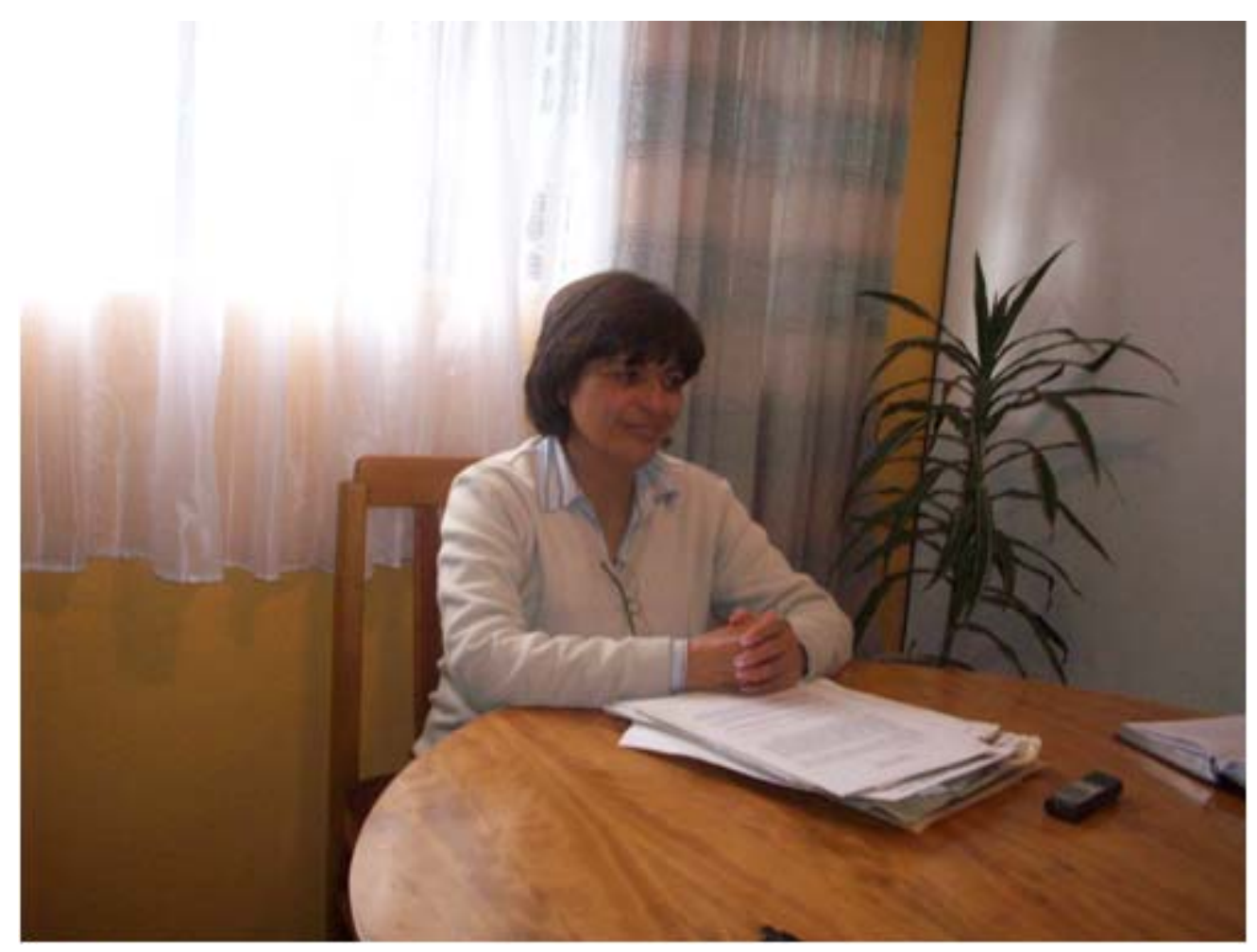

Figura 2. Leonor Martínez, directora de Ecovida. (Tarazona, 2008).

\section{La Asociación para el Desarrollo Campesino -ADC-: entre lo local, lo regional y lo internacional}

La ADC es una organización no gubernamental ambientalista -ONGA- de Pasto, de aproximadamente 33 años de existencia, que se gestó a partir del movimiento cooperativo. Al buscar los orígenes de la ADC encontramos una combinación de actores interesados en alternativas de desarrollo, entre ellos: campesinos del Lago de la Cocha, profesionales de Pasto, miembros del movimiento ambientalista en construcción y agentes de la cooperación internacional, especialmente canadienses. Respecto a los primeros, Eusberto Jojoa Pardo $(1997)^{6}$ narra su aparición de esta manera:

Debido a engaños de los políticos y los intermediarios, que prometían muchas cosas que no podían cumplir, en el año de 1979 comenzamos a hablar de la organización de la Asociación para el Desarrollo Campesino. Reunimos a los presidentes de Acción Comunal, aunque en ese tiempo la gente era desconfiada, y no había la valoración de sí mismos y del entorno. (p. 135) 
Se ha referenciado especialmente por López (1993), cómo en el sector de la Cocha luego de la organización promovida por la Asociación Nacional de Usuarios Campesinos -ANUC- en 1970 quedaron las bases que dieron origen a la reorganización campesina que permiten la fundación de la ADC. Por lo tanto se evidencia que la ONGA, ADC "no surge del vacío", podemos identificar como referentes a la Acción Comunal y a la ANUC como movimientos precedentes que permiten

proyección.

En cuanto a la cooperación internacional en el Lago de la Cocha, su participación ha sido posible debido al puente de profesionales, especialmente de Pasto. De esta manera, "en 1980, la ADC es fundada con el apoyo del grupo canadiense Dynamique Tiers - Monde. Agrupa a campesinos de la región de la Cocha y 17 voluntarios (técnicos, psicóloga, educadores, economistas, etc.) de la ciudad de Pasto" (Ménard, 1993, p. 72). El apoyo de este organismo internacional influencia en ADC una inquietud por el desarrollo alternativo, a través del cooperativismo, de bastante auge en esos momentos:

En 1982 el Proyecto de Desarrollo Cooperativo de la Cocha, Colombia, es presentado a la SDID [Sociedad de Desarrollo Internacional Desjardins, organización de Québec para el desarrollo] para obtener financiamiento. Un estudio de factibilidad es realizado en 1983. Luego de la entrega del informe en Enero de 1984, el proyecto obtiene una parte de los fondos necesarios para su realización, gracias a la Agencia Canadiense para el Desarrollo Internacional, ACDI, en 1985. La duración inicial del proyecto es fijada en tres años. (Ibíd., p. 72)

Ya hacia 1986 se menciona la creación de una cooperativa en inmediaciones del Lago la Cocha:

Se inició con un proyecto específico como el de la Cooperativa La Cocha, el cual fue financiado en el año de 1986 por los canadienses de las cajas populares Desjardins, con 25 socios fundadores. La cooperativa comenzó funcionando con la tienda de autoconsumo e insumos; luego vinieron la comercialización de moras, cuyes, créditos para pequeños proyectos de producción y aquí se indujo el ahorro. La ADC creció con más grupos en otros municipios en el departamento de Nariño, Yacuenquer, Chachagüí, Consacá, La Florida. Todo esto se desarrolló con capacitación continuada por parte de asesores de la ADC. (Jojoa, 1997, p. 135)

Ahora, podríamos preguntarnos: ¿Cómo surge la inquietud en la ADC por los temas ambientales? Se podrían rastrear varias causas de su inquietud ambiental tales como: el hecho de trabajar en un ecosistema tan inspirador como lo es el Lago alto andino de la Cocha, y el contacto de colonos-campesinos con profesionales, estos últimos que vienen de universidades con el afán de aplicar sus saberes bastante influenciados por el auge de los debates mundiales sobre la crisis ambiental planetaria.

Recordemos que el interés económico que funcionó como motor de la colonización fue la explotación de los recursos forestales. El Cultivo de la papa además de servir de base para la alimentación de los habitantes, ha permitido "romper" el suelo, enriquecer su vida orgánica y producir tierra apta para la agricultura. (López, 1993, p. 77) 


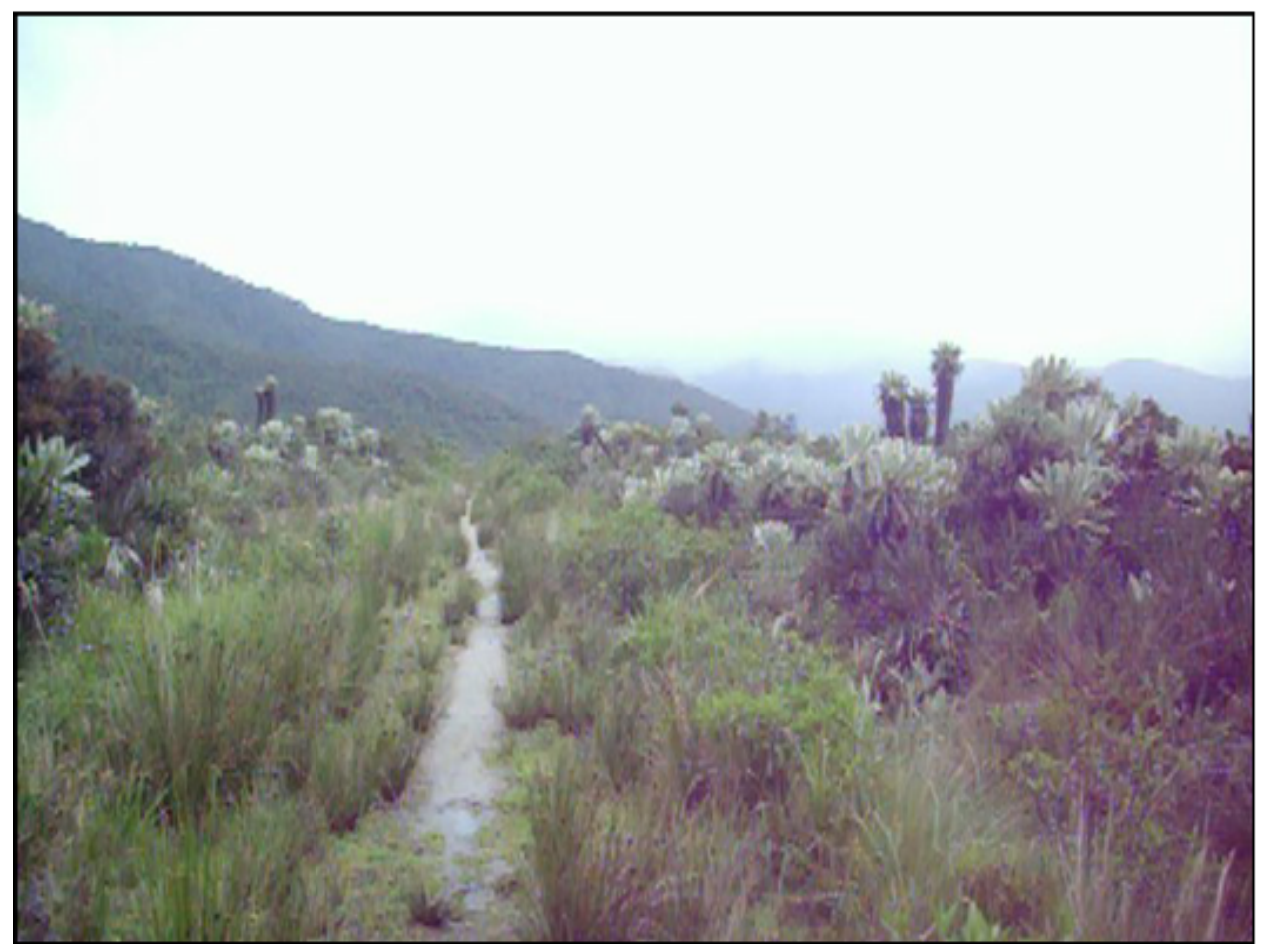

Figura 3. Los Páramos azonales (vereda Santa Isabel, corregimiento del Encano, Pasto) ecosistema defendido por los movilizados. (Tarazona, 2008).

No obstante, la causa fundamental es que las cooperativas obtuvieron influencia directa de la red del movimiento ambiental nacional en construcción en cuanto a organización ambiental:

Entonces no se trata de armar grupos, como decíamos en alguna época, con ecologismo puro, sino penetrar otros. Miremos el caso de los campesinos de la Cocha. Ellos tenían una cooperativa que llevaba ya rato existiendo y la penetramos y hoy es una cooperativa realmente impresionante con las transformaciones que ha tenido en su interior. Antes cortaban bosque para tener leña y carbón y hoy conservan bosque y están en un proceso increíble de conservación de la naturaleza, y es un buen ejemplo para mostrar. Allá hay como 5 cooperativas que están siguiendo este proceso. (Palomino, 1997, p. 120)

Esta influencia del movimiento ambiental nacional posibilitó que diez años más tarde la ADC fuera una de las partícipes en la Fundación de las Reservas Naturales de la Sociedad Civil, llevándose a cabo en Nariño una de su reuniones centrales que dan impulso a su fundación ${ }^{7}$. Posteriormente uno de los fundadores de ADC, Octavio Duque López, fue presidente de la Junta Directiva de la Red Nacional de Reservas Naturales de la Sociedad Civil y representante de las ONGA ante el Consejo Directivo de Corponariño.

El Fondo Mundial de la Naturaleza ilustra cómo la ADC, "aunque comenzaron con programas de desarrollo comunitario, los fundadores comenzaron a darse cuenta de que muchos de sus problemas eran ambientales" (WWF, 31 de julio de 2002).

Se llama la atención respecto a que fue el desarrollo comunitario gestado en torno a la visión cooperativista lo que posibilitó brindar el ingrediente del que se 
carecía al inició de los ochenta. Jojoa (1997) enunciaba: "la gente era desconfiada", a través de los encuentros cooperativos se crean los lazos de confianza propios de las relaciones sociales, lo que trae como consecuencia a la vez "la valoración de sí mismos", su empoderamiento, para luego sí levantar la mirada y "valorar el entorno", el cual de por sí es un privilegio, o, por decir, un "paraíso" a la mirada de los extraños. Al igual, Concepción Matabanchoy ${ }^{8}$, comenta: "si hablamos de Reservas, de conservación en la Cocha, tenemos que hablar de un proceso, porque nosotros tomamos conciencia después de que empezamos un proceso" (citada en Uribe, 2005, p. 19).

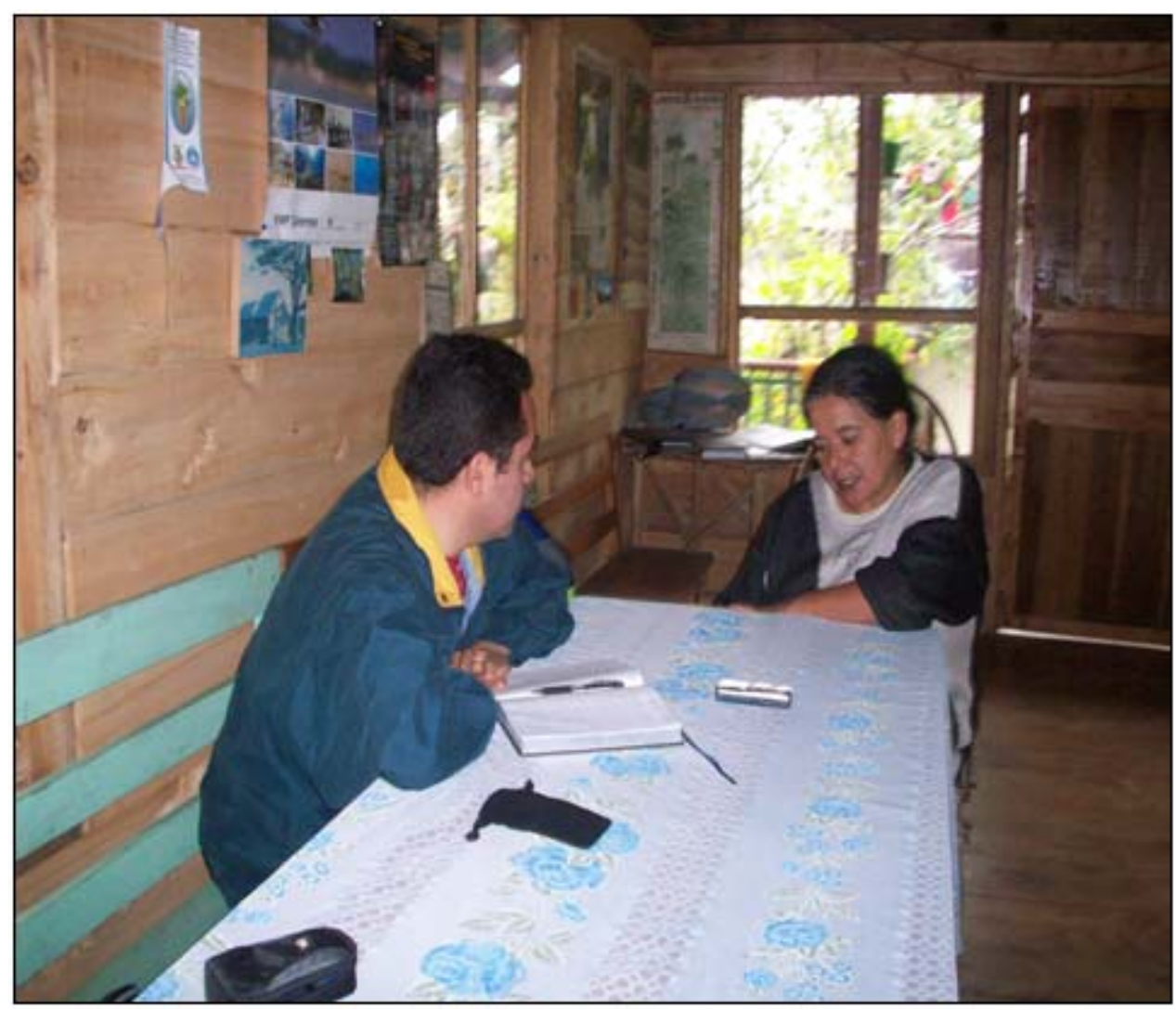

Figura 4. Entrevista con Concepción Matabanchoy, en casa de visitantes Reserva el "Encanto Andino" en inmediaciones del Lago de la Cocha corregimiento del Encano, Pasto. (Tarazona, 2008).

Estos elementos que hemos evidenciado en el origen de la ADC se complementan con el relato de Eybar Insuasty Alvarado ${ }^{9}$, quien nos ilustra cómo, en la satisfacción de la necesidad de buscar un trabajo digno alterno a la explotación de carbón en el Lago de la Cocha, llevó a los lugareños a asociarse y a crear organizaciones puentes entre la participación institucionalizada (las cooperativas) y la redes cotidianas (la minga):

[...] la elaboración del carbón es [...] algo infrahumano, la gente tiene que abrir unos huecos y encerrarse, entonces en esa búsqueda, viendo esa situación, se reúnen [...] para que la gente busque otras alternativas, y es así como surge la ADC, y surge en la Cocha una cooperativa [...] Asoyarcocha [...] las cooperativas [...] realmente, es una forma que no da cuenta de la realidad cultural de los campesinos, entonces, la Cooperativa Asoyarcocha se transforma [...] en la minga Asoyarcocha, se toman todos los conceptos de la minga como unidad, 
como una figura ancestral [...] donde todos solidariamente aportamos, entonces se coge toda esa figura y se convierte esto en la minga Asoyarcocha, que es el actor local de la zona, de la de la laguna de la Cocha y la ADC, al lado sigue desarrollándose su trabajo. (Entrevista con Eybar Insuasty, 2008)

Evidentemente las investigaciones habían mostrado cómo la minga había caído en desuso, sin embargo, "el cambio social introducido por ADC-Coyarcocha ha consistido en modernizar esta institución, darle un nuevo sentido, agregarle valor cultural y utilizar la minga para sacudir los viejos hábitos comunitarios y proponer alternativas" (López, 1993,

p.

$65)$.

A la vez, se presenta una conjugación de la minga con la investigación que se origina de la influencia ejercida por el apoyo de profesores y estudiantes de la Universidad de Quebec, Canadá. La profesora Mary France Labreque ${ }^{10}$ de esta universidad, comienza unas investigaciones con enfoque altamente participativo en compañía de sus estudiantes de tesis de maestría y doctorado donde las comunidades campesinas de las veredas aledañas a la Cocha juegan un papel activo, vinculándose en el acopio y análisis de la información, lo que los prepara como investigadores.

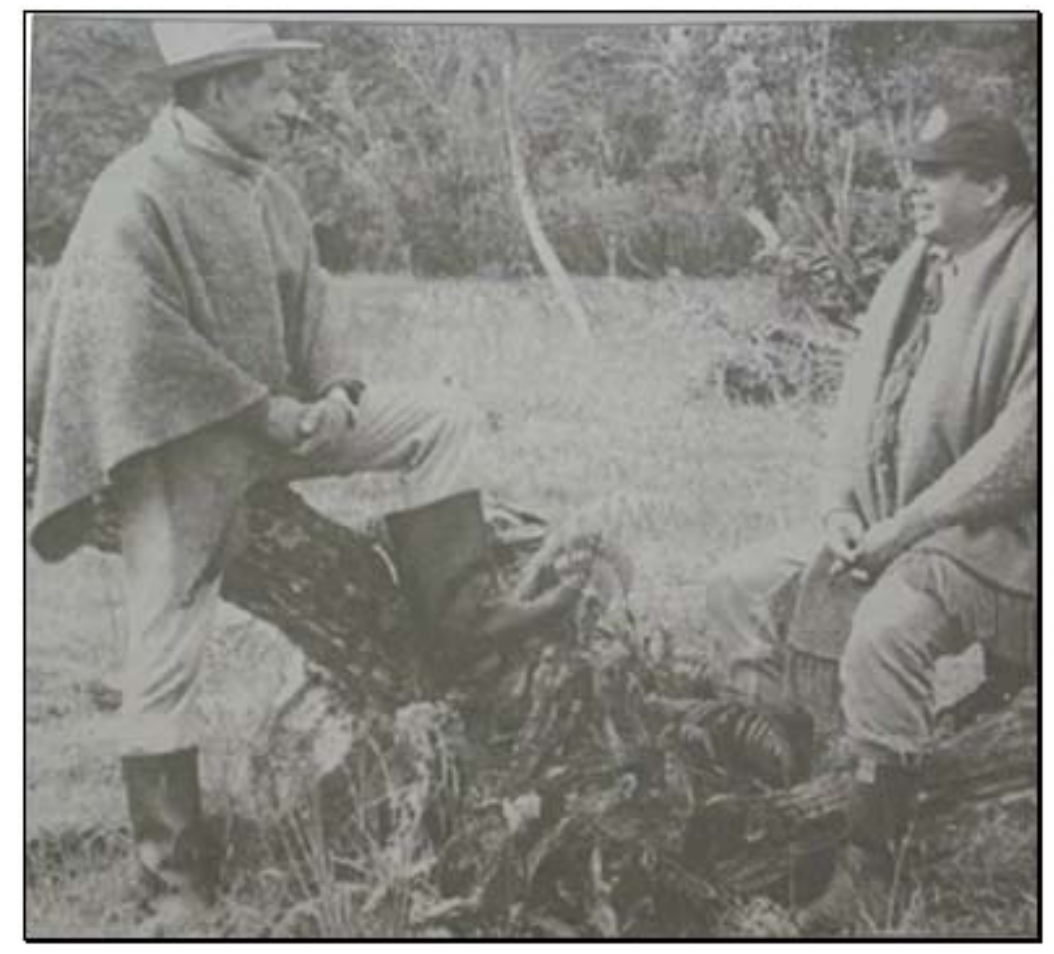

Figura 5. Eusberto Jojoa Pardo (izquierda) y Octavio Duque López (derecha) cofundadores de la ADC. (Diario del Sur, Pasto, 13 de septiembre de 1998, p. 3a).

En el futuro, en el accionar de la ADC, las cooperativas se fusionan con la minga y con la investigación, convergiendo en lo que se denomina las mingas investigativas $^{11}$. En este diálogo que estructura la ADC entre teoría de profesionales-citadinos y la práctica cotidiana de empíricos-campesinos, los primeros deciden con el auge del Desarrollo a Escala Humana adoptar este $\begin{array}{llll}\text { modelo alternativo } & \text { y } & \text { aplicarlo } & \\ & \end{array}$

Las anteriores fuentes muestran que es el interés de citadinos, campesinos, y del movimiento ambientalista nacional en construcción, más la cooperación 
internacional canadiense, los actores principales que permiten el nacimiento de la ADC. Al igual es la fusión y el paso por diferentes dinámicas participativas como son: las cooperativas, la minga, la Investigación-Acción y el Desarrollo a Escala humana, los que permiten una síntesis en la creación y desenvolvimiento de la $A D C$ en el marco de la búsqueda de un desarrollo ambiental alternativo entre lo local, lo regional y lo internacional.

\section{Estrategias de resistencia del Movimiento}

Por la acción estratégica, entiendo, siguiendo a Habermas: "partimos de al menos dos sujetos que actúan con vistas a la obtención de un fin, y que realizan sus propósitos orientándose por, e influyendo sobre, las decisiones de otros actores" (Habermas, 1987, p. 126). Es decir, el fin del Movimiento en Defensa de la Cocha era detener el PMG, esto lo obtuvo el Movimiento por diferentes medios como la unión con otras organizaciones de la sociedad civil, los foros científicos, los encuentros disoñadores y con la propuesta de postular el Lago de la Cocha como humedal Ramsar, esto permitió ejercer influencia en muchos actores de la sociedad local, regional, nacional e internacional.

Además, el concepto de resistencia se contextualiza en movimientos ambientalistas definidos como contemporáneos, los cuales adoptan formas pacifistas de acción como es el trabajo de redes cotidianas que generan solidaridades y que ejercen presiones institucionales, políticas y además se movilizan en campañas espectaculares.

Si remembramos, la ONGA Ecovida mantuvo relaciones con la academia, el cabildeo en la política institucional y los grupos ecológicos pioneros del ambientalismo en Colombia. Y la ADC coordinó la asistencia nacional e internacional que confluyó en la organización campesina alternativa de las Reservas de la Sociedad Civil en la Cocha. Es el encuentro de estas dos ONGA lo que permitió la formación de un movimiento ambientalista local en Pasto, como estrategia de defensa y protección del humedal alto andino amenazado por los intereses de proyectos que desde la racionalidad económica de líderes locales y nacionales quieren imponer como panacea un desarrollo tradicional a través de la sociedad $\mathrm{PMG}^{13}$. 


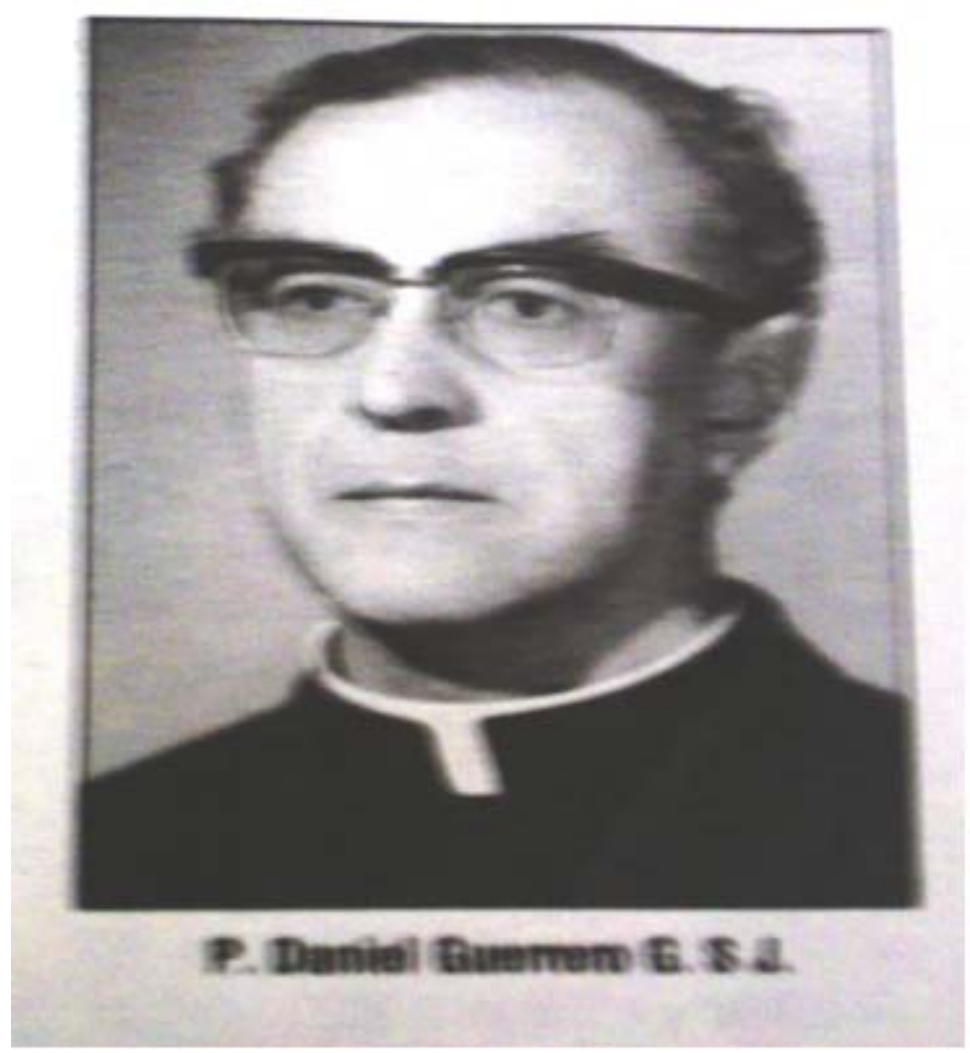

Figura 6. Sacerdote Jesuita promotor del PMG. (Diario del Sur, Pasto, 4 de octubre de 1996, $\quad$ p.

La ADC y Ecovida en primera instancia se acercan, establecen alianzas y se encuentran en el objetivo común de hacer frente al PMG, al que veían como una amenaza para la sostenibilidad socio-ambiental de la Laguna de la Cocha.

Nosotros no éramos muy cercanos a ellos, incluso teníamos diferencias graves, graves, pero a raíz del PMG [...] unimos nuestras virtudes y nuestras fortalezas y pues, no las respetamos, pues porque tenemos diferencias hasta ahora. Pero hubo mucha unión a raíz de eso y mucho grupo se unió, por ejemplo el grupo del cabildo indígena, que era contrario a la ADC, estuvo con la causa contra el PMG, a pesar de que con ADC no tenía muy buenas relaciones y nosotros éramos hay como intermedios, ¿sí me entiende? Entonces ellos no se hablaban con los de ADC pero sí se hablaban con nosotros, y nosotros nos hablábamos con todos. (Entrevista con Leonor Martínez, 2008)

Se han registrado otras diferencias de la ADC con el sindicato campesino Fundación Nacional Sindical Unitaria Agropecuaria -Fensuagro-, pareciera ser originadas en las formas de lucha y en la ilegitimidad de la representación, que llevó a este sindicato a manifestarse a favor del $\mathrm{PMG}^{14}$. Varios autores han mencionado cómo las diferencias y fisuras son constantes en los movimientos sociales, su pluralidad y heterogeneidad se manifiesta en un constante campo de luchas. Cohen y Arato asienten, "no obstante los movimientos sociales no van dirigidos contra el Estado; implican confrontaciones entre adversarios sociales, civiles, dentro y acerca de las instituciones de la sociedad civil" (2000, p. 577).

Las estrategias de lucha del movimiento se consolidan en la unión de grupos de ONGA que habrían tenido disparidades en el pasado. Es decir, el PMG aglutina 
el encuentro afín a un enemigo común. Además se colonizan otros actores en los que se busca solidaridad por parte del movimiento ambientalista local haciéndolos sus aliados, éste es el caso de la UDENAR donde se conforma el Grupo ecológico "Amigos de la Cocha".

"Los movimientos también generan nuevas solidaridades, alteran la estructura asociativa de la sociedad civil y crean una pluralidad de nuevos espacios públicos, a la vez que amplían y revitalizan los espacios que ya están institucionalizados" (Ibíd., p. 592).

El Grupo ecológico "Amigos de la Cocha" se convoca a estudiar desde diferentes disciplinas el Lago de la Cocha, hacen activismo en contra del PMG, y son parte de la organización del Foro Científico sobre la Cocha. En palabras de Yonny Mosquera $^{15}$, líder de este grupo ecológico, menciona lo siguiente:

[...] recuerdo que lo que hicimos fue [...] hicimos como un par de reuniones, unas tres, cuatro así en algunas veredas de la Cocha, con campesinos, como para mostrarles como la otra cara de la moneda, porque Arévalo [hace referencia al ingeniero Francisco Arévalo, gerente de la sociedad PMG] ya había pasado vendiendo un proyecto, convenciéndolos, ofreciéndoles plata... [Se] pensó como una estrategia [...] un Foro en el cual pretendía que se expusieran todos los puntos de vista, frente al proyecto, incluyendo el de los que estaban a favor y los que estaban en contra, ¿no?, [se les] envió información a algunos científicos reconocidos a nivel del país [...] sobre el proyecto sobre la zona y los invitó para que vinieran a la época del Foro, entonces la idea era que primero ellos pudieran recopilar toda la información e hicieran un recorrido por la zona y después pudieran intervenir en el Foro, ¿no?, y dar su concepto, qué les parecía el proyecto, qué opinión tenían... (Entrevista con Yonny Mosquera, 2008).

Al vincular a la UDENAR en la atención al PMG y su impacto sobre la Cocha, se busca aplicar la misma estrategia que dio resultados en el pasado con la lucha local contra las siembras de pinos y eucaliptos. La estrategia fue convocar a expertos, científicos que corroboraran el daño al introducir especies exóticas en estas latitudes. Al igual, para este momento la resistencia al PMG también se centró desde la UDENAR, Ecovida y la ADC el convocar a un Foro Científico donde participaran expertos ${ }^{16}$. 


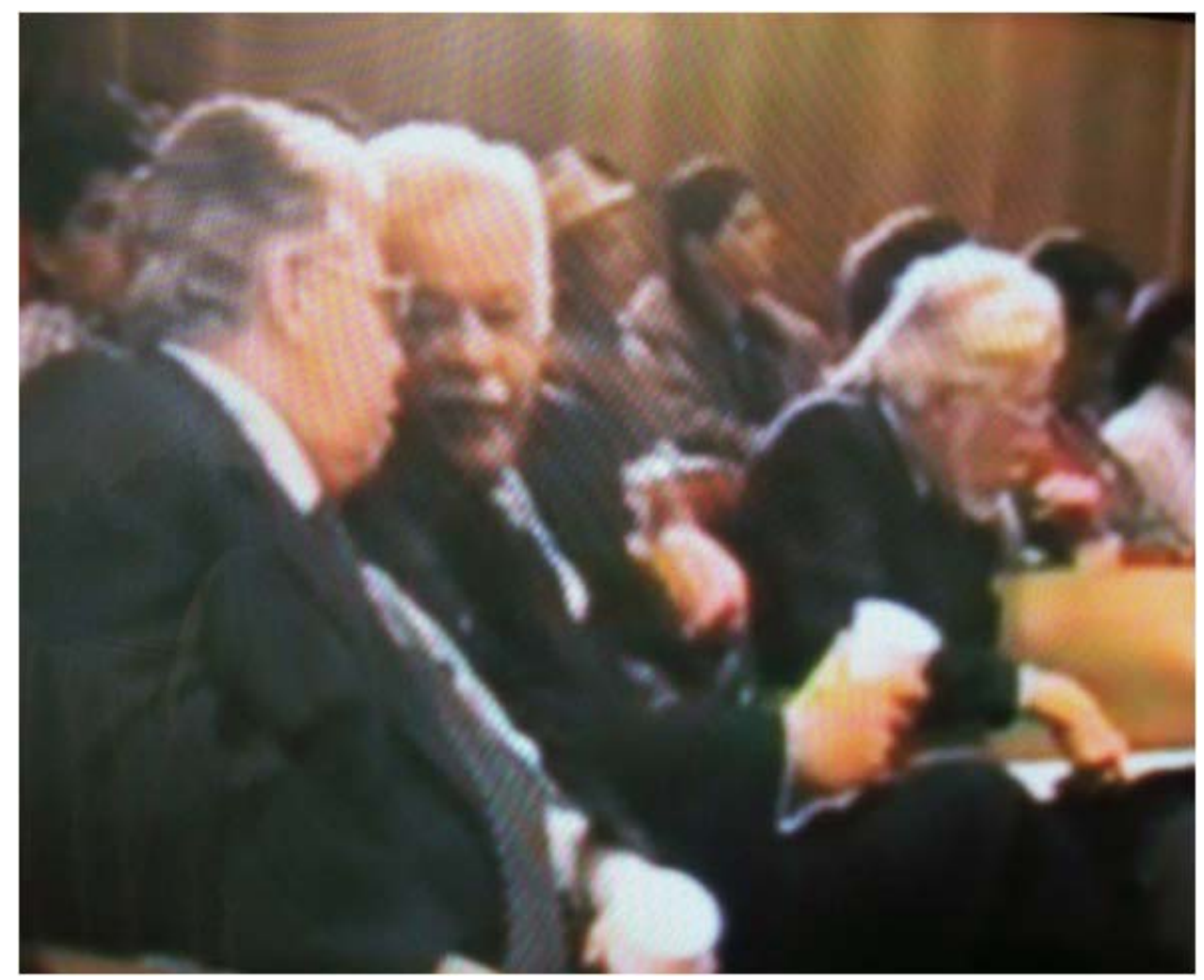

Figura 7. Foro Científico, de izquierda a derecha: Luis Eduardo Mora Osejo, José Lozano, Thomas Van Der Hammen. (Imagen del Video del Foro Científico, UDENAR).

Habermas (1998) ilustra a cabalidad el papel de la influencia de los expertos, que junto a otros actores de la vida pública como son los miembros de la sociedad política, los grupos conocidos, de figuras del espectáculo, generan debate en el espacio de la opinión pública, que es donde se manifiestan los movimientos sociales:

En el espacio de la opinión pública se ejerce influencia y en él se lucha por ejercer influencia. En esa lucha no sólo entra en juego el influjo político ya adquirido y acumulado (por acreditados ocupantes de cargos públicos, por partidos políticos establecidos, o por grupos conocidos como Greenpace, Amnistía Internacional, etc.) sino también el prestigio de grupos de personas y también de expertos que han adquirido su influencia en espacios públicos más especializados (por ejemplo, la autoridad de eclesiásticos, la fama de literatos y artistas, la reputación de científicos, el renombre y relumbre de estrellas del deporte y del mundo del espectáculo, etc.). Pues en cuanto el espacio público se ha extendido más allá del espacio de las interacciones simples, se produce una diferenciación entre organizaciones, oradores y oyentes, entre arena y galería, entre escenario y espacio de espectadores. (p. 443-444)

En el caso del movimiento ambientalista local de Pasto en contra del PMG se acudió a la influencia de sociedad política y a "grupos conocidos" como evidenciaremos más adelante. En el Foro Científico fue la "reputación de científicos" de trayectoria nacional quienes tomaron el papel de "oradores", junto con los dueños del proyecto y la WWF. Los oyentes: estudiantes, profesores y habitantes campesinos de la Cocha e interesados. El objetivo del Foro Científico 
era poner en común los intereses en controversia, sin embargo, en dicho evento se establecieron por la ADC y Ecovida todas unas acciones estratégicas: la primera, que el Foro se denominara "Foro Científico sobre la Cocha", nunca mencionar el PMG para ignorar la contraparte. La segunda estrategia, buscaba establecer previamente quiénes hablaban y quiénes no lo hacían, turnos y silencios, en razón de que en pasados debates públicos, los dueños del proyecto hablaban siempre hasta en final, dejando a sus opositores sin tiempo de refutar, quedando en las audiencias la sensación de supremacía del PMG. El Foro Científico convocó a otras instituciones como la Secretaría de Medio Ambiente Departamental de Nariño, la Coordinación de Parques Nacionales, y ciertos programas y facultades de la UDENAR.

El Foro Científico comienza a generar las sinergias de la solidaridad e identidad entre estudiantes, profesores, campesinos, citadinos, ONG, expertos e institucionalidad y es un triunfo del movimiento ambientalista local sobre la sociedad económica PMG.

Hay una categoría de acción que puede observarse en los conflictos sociales, a la que se puede entender no preguntando qué ganancias y pérdidas producirán para los actores, sino si producirán solidaridad. Estas acciones denotan el proceso de formación de una identidad. (Pizzorno, 1978 citado en Cohen \& Arato, 2000, p. 616)

Al igual, desde la ADC surge una estrategia que convoca a nacionales y extranjeros a los encuentros "Disoñadores". A León Octavio Osorno, se le atribuye la creación de la palabra "disoñar" y es lo que hacen quienes diseñan su vida de acuerdo con sus propios sueños (Duque, 1997). Los encuentros "Disoñadores" estaban fundamentados en el diálogo de saberes, intelectuales y el saber popular se encuentra para hablar del pasado, presente y futuro: "Aquí se mezclan campesinos, jóvenes, ambientalistas, intelectuales, mujeres, médicos, periodistas bajo el sino común de andar tercamente haciendo camino propio contra la condena que pretende excluirnos y convertirnos en cifras o en máquinas" (ADC y Fundación Colombia Multicolor, 1997, cubierta).

Se desarrollan dos encuentros de este tipo, subyace en el fondo el interés por llamar la atención del país y del mundo sobre el Lago de la Cocha ${ }^{17}$, a la vez, es un escenario que permite el fortalecimiento del liderazgo local y la ampliación del horizonte en líderes naturales.

En ese evento la particularidad cuál era, que era bien interesante, que era un diálogo, muy, muy chévere entre los académicos, si, bueno, vinieron una gran cantidad de académicos. Pero también el diálogo desde la experiencia de los campesinos, igual hablaba William Ospina o Manfred Max-Neef, daban una conferencia, igual daban una conferencia Eusberto Jojoa o la Conchita Matabanchoy, entonces era la parte muy académica pero también la parte práctica y la experiencia vivencial. (Entrevista con Eybar Insuasty, 2008).

Se pueden rastrear inquietudes de lo ambiental en muchos de los participantes de los encuentros "Disoñadores"18 reminiscencias de su vinculación con la Casa Palermo en Bogotá en donde se congregaban líderes del movimiento ambientalista en construcción. "También llegaron los amigos de lejos. Vino León Octavio con su balita que no quería matar y el flaco Jaime Quijano desde su Popayán y los otros flacos Luís Alberto Ossa y Néstor Javier Velásquez desde Pereira" (Bustos, 1997, p. 210). Ello corrobora enlaces de la lucha local en contra del PMG con miembros del movimiento ambientalista en construcción en Colombia, hay redes y cadenas de 
movimientos.

De todas estas discusiones especialmente del Foro Científico, surge la idea de buscar una figura de amparo para la Cocha, y por la confluencia de otras organizaciones como la WWF y Asdes de Cali se decide en el llenado de la Ficha Ramsar buscando declarar este humedal alto andino como zona de protección internacional. Esta propuesta implicó una consulta a los habitantes de la Cocha, que se realizó de forma muy rápida y en secreto para evitar que los dueños del proyecto se percataran y reaccionaran.

La WWF puede ser entendida, como un "grupo conocido" (Habermas, 1998) al igual que Greenpeace o Amnistía Internacional, que permite generar influencia en el espacio de la opinión pública. La llegada de la WWF a Colombia data de 1964; unos de sus primeros focos de atención son la protección de especies y conservación de áreas protegidas; en la década de los ochenta la WWF hace contactos con la ADC.

Fue es esta década [ochenta] en que se inició el trabajo de apoyo a varias ONG para la conservación de áreas específicas, reforzando el trabajo realizado en educación, particularmente en los Andes Centrales con la Fundación Herencia Verde (FHV), La Planada con la Fundación para la Educación Superior (FES), Bahía Málaga con Cenipacífico, Farallones de Calí con la Fundación Farallones, La Cocha con la Asociación para el Desarrollo Campesino (ADC), y la Ensenada de Utría con la Fundación Natura. (Duque \& Higging, 1996, p. 36)

Hacia 1993 la WWF $^{19}$ discute directrices para un proyecto de Educación Ambiental en Colombia con varias organizaciones sociales y ambientales, y en 1996 se planifica que en los próximos años venideros, "igualmente fomentará las iniciativas de trabajo de Educación Ambiental en organizaciones, en los proyectos de conservación como FHV, la Red de Reservas de la Sociedad Civil, ADC y otras" (Ibíd.).

Para el caso de ADC, la WWF diseña en compañía de Asdes de Cali, "una estrategia de participación ciudadana para el Proyecto Multipropósito Guamués" en el marco del Proyecto de Implementación sobre el Convenio de Diversidad Biológica. El objeto central de la estrategia plantea lo siguiente: "se diseña para abordar un problema concreto: la amenaza que un mega proyecto impone sobre un ecosistema en particular y el impacto en la vida de las comunidades de la zona" $^{20}$. En estos encuentros de la ADC con la WWF y Asdes se generaron sinergias en torno al proyecto para priorizar el Lago de la Cocha como Zona Ramsar, siendo una estrategia de resistencia al PMG.

De aquí en adelante se inicia un trabajo en una red interinstitucional que involucra a la UDENAR, Corponariño, Ministerio del Medio Ambiente, Red de Reservas de la Sociedad Civil y Parques Nacionales obteniendo como resultado la declaración (Decreto Ley No. 698 del 18 de abril de 2000) del Lago de la Cocha como humedal Ramsar. Sin lugar a dudas éste fue el punto de quiebre del PMG; veamos la impresión de Ana María Fuentes ${ }^{21}$ al respecto:

Entonces cuando eso fue ya declarado sitio Ramsar en el 2000 [...] digamos elevó mucho más la pesa sobre la valoración de la Cocha y ya el PMG fue disminuyendo toda su [...] validez de hacer una represa [...] Pero ya políticamente, no había, ¿qué?, como amigos del proyecto, eso fue, perdiendo pues todos, sus favores digamos políticos de alcaldía de Pasto, gobernación de Nariño y también pues priorización dentro del Gobierno nacional [...] El PMG además se fue desmembrando, ya no tenía oficinas, se fue la gente que estaba 
trabajando en eso [...] hasta que el mismo gerente del PMG se fue, se fue de Pasto, ya el proyecto quedó ahí. (Entrevista con Ana María Fuentes, 2008)

La estrategia de buscar la declaración de la Cocha como humedal de importancia internacional fue un trabajo de los distintos nodos que confluyeron en la red de resistencia al PMG y en el cual se vincularon instituciones del orden nacional e internacional. A medida que el PMG continuaba en sus estudios y gestiones de alto nivel, el movimiento ambientalista local avanzaba en la propuesta para convertir a la Cocha en Zona Ramsar.

Hemos conocido cómo a partir de la confluencia de dos fuerzas, la primera, desde la ONGA Ecovida que a partir de la estrategia del Foro Científico en la UDENAR donde figuras "consagradas" de reputados científicos o expertos generan influencia en el departamento de Nariño para llamar la atención en la opinión pública regional, nacional e internacional sobre los impactos que generaría el PMG sobre el humedal alto andino de la Cocha; la segunda, a partir de la ONGA ADC, con los encuentros "Disoñadores" y la estrategia de vincular a la lucha a un "grupo conocido" como la WWF, buscaba generar influjo político en el contexto nacional e internacional.

Estas dos ONGA generaron un trabajo en red que vinculó a otras organizaciones gubernamentales y no gubernamentales que ejercieron influencia, que trajo como consecuencia la decisión por parte de la secretaría de Ramsar de declarar el Lago de la Cocha en el año 2000 como zona de importancia internacional. Esta declaración obtuvo el fin último del movimiento, detener las pretensiones de la sociedad económica de Pasto por proseguir en la búsqueda de la licencia ambiental del PMG.

Los movimientos ambientalistas locales en Pasto al expandir sus redes también generaron influjo sobre la sociedad política local, regional y nacional en aras de su objetivo culmen de la negación de la licencia ambiental por parte del Ministerio del Medio Ambiente al PMG. A continuación, queremos mostrar cómo se desarrollo dicho proceso.

\section{La influencia sobre la sociedad política}

La "política de influencia" se dirige al Estado y la sociedad económica para abrir espacios para nuevas interpretaciones de necesidades (Cohen \& Arato, 2000). En este momento el interés del movimiento era generar la necesidad en el Estado y su institucionalidad (que en este apartado definimos como sociedad política) de proteger el Lago de la Cocha del impacto del PMG, por tanto se les persuade para obtener esta nueva interpretación, que se palpe en el accionar de su política pública.

Se parte por conjugar alianzas entre el sector de la sociedad civil como estrategia de resistencia que ha llevado a aglutinar un foco del movimiento ambientalista local en respuesta al PMG. Este foco ha colonizado con diferentes estrategias a otros sectores como la sociedad política (alcaldes, gobernadores, concejales, parlamentarios, asambleístas, presidentes, CAR) para hacerlos sus aliados o que cumplan la labor constitucional que se les ha encomendado.

Desde la campaña a la presidencia, a Ernesto Samper Pizano se le veía muy interesado en sacar adelante el Multipropósito como solución para Pasto, "además, volver al PMG parte integral de su administración, pues permite salidas a las deficiencias de agua potable y energía eléctrica para Pasto, como 
precandidato presidencial promete incluir en el Plan de Desarrollo" (Diario del Sur, noviembre 13 de 1993, p. 3a). Es por esto que las ONGA de la región, recién posesionado Samper como gobernante, deciden enviarle una carta de rechazo a sus posturas de promoción del PMG, veamos uno de sus apartes:

Preocupados por el manejo irresponsable de la información dada acerca del PERFIL del PROYECTO MULTIPROPÓSITO GUAMUÉS, que ha ocasionado, en candidatos presidenciales, manifestaciones de apoyo irrestricto al mismo por considerarlo la panacea para el desarrollo de Nariño, queremos prevenir a su gobierno sobre los compromisos que en este sentido adquiera con los nariñenses. ${ }^{22}$

Durante el gobierno Samper (1994-1998), el Ministro del Medio Ambiente, José Vicente Mogollón visitó por dos días a Pasto y se apersonó del tema del PMG visitando el Lago de la Cocha. En dicha visita el ministro estuvo acompañado por Antonio Navarro Wolf ${ }^{23}$ y como guías estuvieron miembros de la ONGA ADC, allí las diferentes comunidades asentadas en el Lago de la Cocha expusieron sus inquietudes de rechazo al PMG. A la prensa local el ministro manifestó: "que el Presidente sí ha estado apoyando activamente al PMG, pero que por Ley del Ministerio del Medio Ambiente tiene la función de defender la naturaleza y garantizar el desarrollo sostenible" (Diario del Sur, noviembre 26 de 1996, p. 12a).

A nivel local se exigió por parte del movimiento ambientalista a la Corporación Autónoma Regional de Nariño -Corponariño-, el cumplimiento de su misión encomendada en la Ley 99 de 1993. De esta institución, en los inicios del PMG, se habló de que sería la ejecutora del proyecto e invirtió 130 millones de pesos en éste ${ }^{24}$. La pregunta de los líderes del movimiento local, es: ¿cómo Corponariño como autoridad ambiental a la vez cumplía una misión de juez y parte del PMG ${ }^{25}$; es por esto que la presión del movimiento ambientalista local se dio a la tarea de hacer retirar las oficinas del PMG de Corponariño. Al igual, durante visita del Ministro de Medio Ambiente, José Vicente Mogollón, a Pasto en noviembre de 1996, los movilizados lo conducen al Lago de la Cocha, donde conoce en forma directa las desavenencias en contra del PMG.

A la vez, la influencia del sector ambientalista posibilita que representantes populares del departamento como el gobernador de Nariño y el alcalde de Pasto de la época, dirijan carta a la directora ejecutiva de Corponariño haciéndole peticiones similares:

Considerando las declaraciones de la comunidad ambientalista regional, que reclama mayor atención sobre el estudio de impacto ambiental, antes de avanzar más en los estudios de ingeniería, le solicitamos comedidamente a Corponariño que licite públicamente la ejecución del análisis ambiental del PMG [...] De esta manera Corponariño cumplirá con sus funciones ambientales definidas en la Ley 99/93 y aplicará los recursos económicos exactamente para el cumplimiento del objeto al que fueron destinados. ${ }^{26}$ 


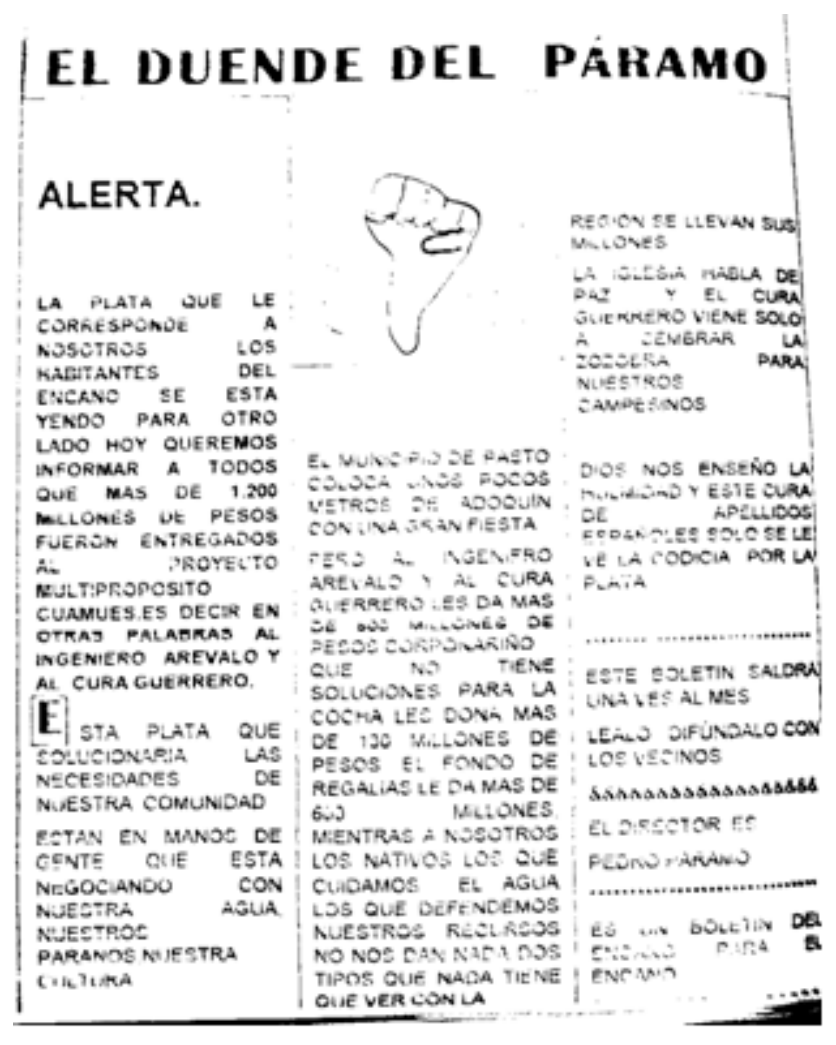

Figura 8. Boletín informativo \# 1 del Corregimiento del Encano, Noviembre de 1996. (MAVDT, Expediente 509, carpeta 1, folio 161).

El cabildeo a Corponariño, confirma:

[...] los movimientos feministas y ecologistas, el litigio, la supervisión muy de cerca de las agencias gubernamentales y el cabildeo profesionalizado pueden ser muy efectivos si van acompañados de un movimiento nativo y si hay una base claramente legal y administrativa para su realización. (Jenkins \& Eckert, 1986 citados en Cohen \& Arato, 2000, p. 570)

Llama la atención un Derecho de Petición con un lenguaje muy elaborado que es enviado al Ministro de Ambiente, Verano de la Rosa, por parte de la Organización Comunitaria para el Desarrollo de la Cocha -OCD- que exige que sus opiniones y decisiones de las comunidades sean tenidas en cuenta al momento de tomar decisiones, veamos:

Las 18 veredas de la OCD, todos hijos de estas tierras, nacidos y criados en relación con el agua, más de la mitad de nuestra vida a transcurrido en contacto con ella, la hemos visto en invierno y verano con sol y con nubes, aquí hemos aprendido a navegar, pescar, trabajar y aquí también hemos construido nuestros sueños y nuestros afectos. ${ }^{27}$

Conexa hay una estrategia del movimiento ambientalista local por incidir en las decisiones en la élite dirigente del departamento de Nariño y del municipio de Pasto. Estos últimos, en principio, legislan, lideran y gestionan ${ }^{28}$ recursos para estudios previos que impulsen el PMG en la búsqueda de una solución a la "escasez de agua que vive Pasto". A la vez unida a la intención de la búsqueda de desarrollo energético para el Sur de país y la frontera con Ecuador, proyecto 
éste que viene siendo impulsado por miembros de la sociedad económica y gestores del desarrollo.

Ya durante la administración de Antonio Navarro Wolf es importante destacar la "política de influencia" ejercida por miembros de la ONGA Ecovida:

En la época de Navarro yo fui... consejera de Planeación territorial y para serle sincera, le voy a comentar una expresión de Navarro, cuando yo le mostraba la inquietud nuestra, que nosotros teníamos frente al proyecto. Me decía: Yo le pongo una vela a Dios y otra vela al diablo, entonces yo le decía, Doc, Pero Doctor, usted tiene que estar de lado de la ciencia y del derecho, entonces eso científicamente y desde el punto de vista legal tiene muchísimos problemas. Me decía, no, Leonor espérate a los estudios, no te aceleres, no te adelantes, y, yo, le digo, yo, me la pasaba era peleándole a Navarro, y yo le peleé hasta el último momento, hasta el último momento. Porque, yo le decía, Doctor es que no entiendo, no entiendo, cómo usted pueda estar, con más favorabilidad para allá, que acá y, se dice, y yo me inclino pero es una cosa como de percepción, de que él empoderó mucho el proyecto, mucho, mucho, mucho. Porque a nosotros gente nos venía a decir, no es que, es que Navarro es el que tiene el proyecto así tan empoderado, nos venían a decir, y yo le decía, Navarro tú, me conoces, yo le peleé hasta el último momento. (Entrevista con Leonor Martínez, 2008)

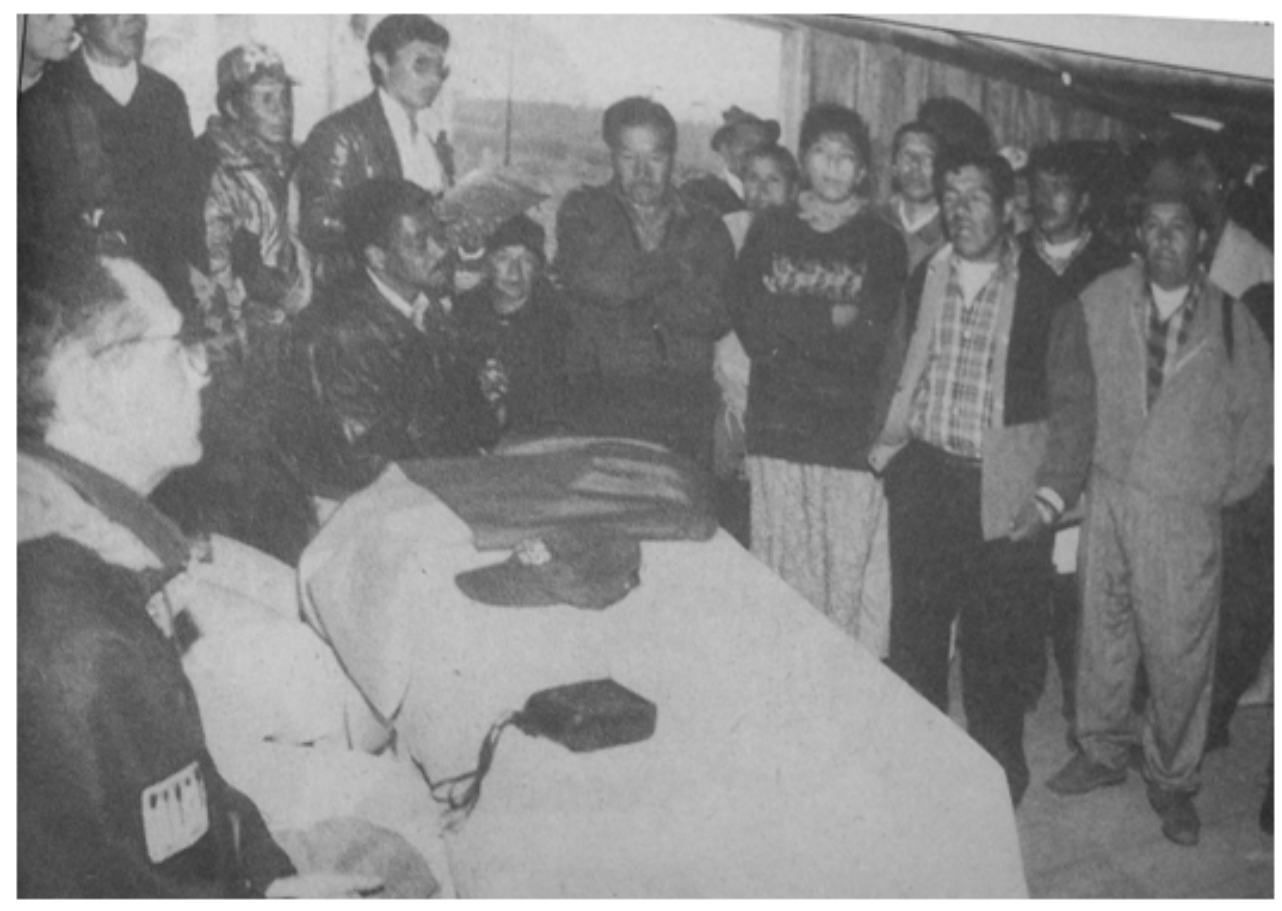

Figura 9. Campesinos, carboneros y cortadores de leña, del corregimiento El Encano (Pasto). Elevando voz de protesta ante el Ministro de Ambiente, José Vicente Mogollón, por los impactos del PMG. (Diario del Sur, Pasto, 25 de Noviembre de 1996, p. 11a).

Llama la atención del aparte del relato, en primera instancia la frase: "Yo le pongo una vela a Dios y otra vela al diablo", algo muy típico de los políticos, su ambivalencia, frente a las decisiones trascendentales. En segunda instancia es 
de destacar la confianza que Navarro pone en los "estudios" que arroje el aparato científico-técnico, sobre el PMG, como certeza para su desarrollo. Al igual Luís Eduardo Sánchez miembro de ECOVIDA, comenta cómo Navarro "ha manifestado a los ambientalistas de la ciudad que está de acuerdo en que los estudios de impacto ambiental y social para el [PMG] sean de la más alta calidad científica y técnica" (Diario del Sur, Pasto, 19 de junio de 1995, p. 6A). Éste poner en manos de los técnicos y la ciencia, la última palabra, también implica riesgos, como se expresa en el siguiente argumento:

Como la altiva seguridad con la cual la ciencia como institución pública propone sus certezas no corresponde a la realidad de la investigación científica y a la conciencia de un número creciente de científicos. Los límites del conocimiento, el carácter hipotético de la investigación, el área desproporcionada de incertidumbre dentro de la cual se mueven las decisiones y las elecciones de los científicos, son elementos que deben entrar en el discurso público sobre la ciencia. Contribuyendo, de esta forma, a debilitar, si no a desmantelar, los fundamentos de aquella fe tecnológica que confía a la ciencia las esperanzas de salvación de las catástrofes que son una amenaza. (Melucci, 2002, p. 149)

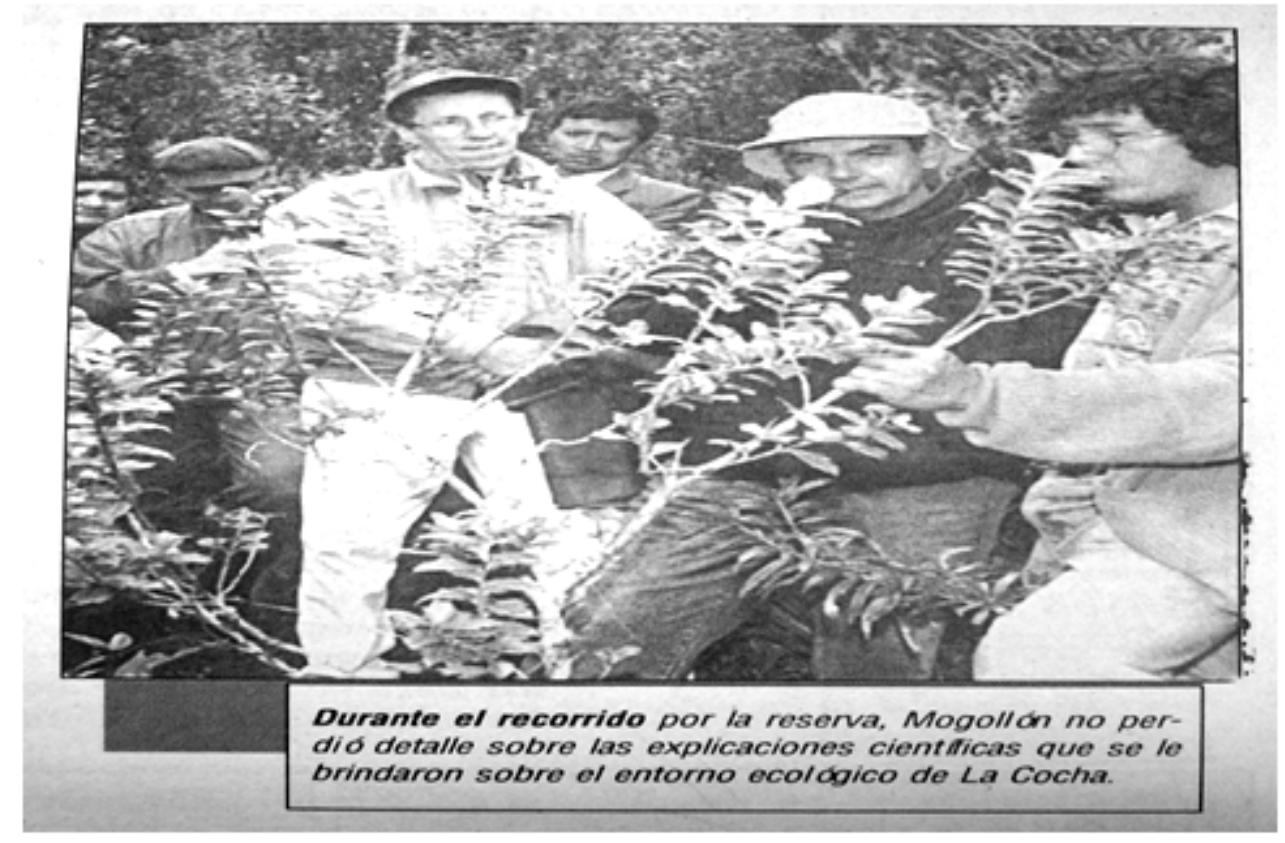

Figura 10. Visita a las inmediaciones del Lago de la Cocha en la vereda Santa Teresa, Reserva Tunguragua (corregimiento del Encano, municipio de Pasto). Antonio Navarro Wolf, José Vicente Mogollón y Oscar Duque administrador de la Reserva. (Diario del Sur, Pasto, 26 de noviembre de 1996, p. 3a).

Por tanto, la ambivalencia de Navarro optaría más por decisiones óptimas de costo-beneficio, basadas en el paradigma de la ciencia, que en las democracias consensuadas, donde los gobernantes buscan enriquecer el debate con diferentes posiciones para llegar a decisiones más acertadas, y es allí donde los movimientos sociales ejercen influencia para que sus posiciones prevalezcan en la toma de decisiones ${ }^{29}$.

En tercera instancia es de resaltar del relato, "no entiendo, no entiendo, cómo usted pueda estar con más favorabilidad para allá que acá". Leonor imaginaba que por la trayectoria de Navarro podría estar más cercano a los intereses de los 
ambientalistas y de las comunidades más desfavorecidas, como los habitantes campesinos del corregimiento del Encano. Esta faceta de Antonio Navarro de no escuchar y comprender los movimientos ambientalistas ya ha sido documentada en la Historia del Movimiento Ambiental:

En ese sentido nos acercamos al M-19, cuando se estaba desmilitarizando en Santo Domingo. Ellos querían estructurar su programa político, su planteamiento político, nos reunimos durante tres días con los directivos y no fue fácil convencerlos, creo que por el realismo político de Antonio Navarro. El que más comprendió la idea fue Carlos Pizarro, a Navarro lo que le interesaba era ganar las elecciones y él no veía allí ninguna plataforma para ganar las elecciones; sencillamente no quisieron adoptar la propuesta de un ideario ambiental como base de un movimiento político, ese intento fracaso. Después, cuando la constituyente, volví a intentarlo nuevamente con el M-19. Para ese entonces habíamos creado el MAYDA y estábamos iniciando el Instituto de Estudios Ambientales de la Universidad Nacional. Le enviamos una carta a Antonio Navarro proponiéndole la necesidad de organizar una constitución ambiental y que ellos fueran los abanderados; ni siquiera contestaron la carta. (Ángel, 1997, p. 56-57)

Si volvemos al final del segmento de relato de Leonor Martínez, se percibe un desencanto por el líder. No obstante, resulta que este desencanto por los líderes políticos es algo que cada vez más se percibe, en la ola democratizante de América Latina: "sean gobiernos de izquierda o de derecha siguen el mismo modelo de desarrollo, la única resistencia es de los pueblos" (Palacin, 2008). Si retornamos a Mellucci, este teórico ha documentado cómo los movimientos sociales contemporáneos están más allá de las izquierdas y las derechas, veamos:

Tradicionalmente, la "derecha" demostraba una orientación hacia el pasado, mientras que la "izquierda" demostraba una orientación hacia el futuro. Pero la aparición de los "movimientos" sociales contemporáneos ha dejado, sobre la conciencia colectiva, la impresión de que vivimos en una sociedad sin futuro, no sólo porque el futuro se ve amenazado por la posibilidad de una catástrofe mundial, sino porque el problema central de los sistemas complejos es el mantenimiento del equilibrio. El supuesto carácter "antimoderno" de los "movimientos" consiste, en efecto en su proclamación del fin del progreso lineal y en su afirmación del sentido de lucha por el presente, del cual depende también nuestro futuro. (Melucci, 2002, p. 168)

Se ejercieron influencias en otras instituciones regionales que comienzan a incidir en la decisión que debe tomar el Ministerio del Medio Ambiente -MMA- sobre la licencia ambiental a otorgar al PMG como las procuradurías regionales. "Antes de emitir la licencia ambiental al [PMG], se reconsidere dicho proyecto, considerando que en el año 2000 se declaró el Lago de la Cocha como humedal de importancia internacional" ${ }^{31}$.

Al final de la puja, la licencia ambiental al PMG es negada por parte del MMA, veamos su pronunciamiento:

Declarar que ninguna de las alternativas presentadas por la sociedad Proyecto Multipropósito Guamués S.A. E.S.P. para el Proyecto Multipropósito Guamués 1 es viable; Contra la presente providencia procede recurso de reposición ante el Subdirector de Licencias Ambientales de este Ministerio. (Auto No. 067 del 17 de diciembre de 2001 del MMA, Artículo $1^{\circ}$ y $5^{\circ}$, p. 14) 
La sociedad PMG presentó recurso de reposición argumentando:

La Carencia y equilibrio y equidad en el tratamiento y sustentación del auto; la realización de una interpretación del convenio RAMSAR, parcializada y llena de inconsistencias; sustentar la negativa en afirmaciones erróneas y equivocadas. Referentes al manejo del embalse y su posible impacto negativo sobre el Santuario de Flora y Fauna de la Corota. (Auto No. 467 del 9 de mayo de 1992 del MMA, p. 3)

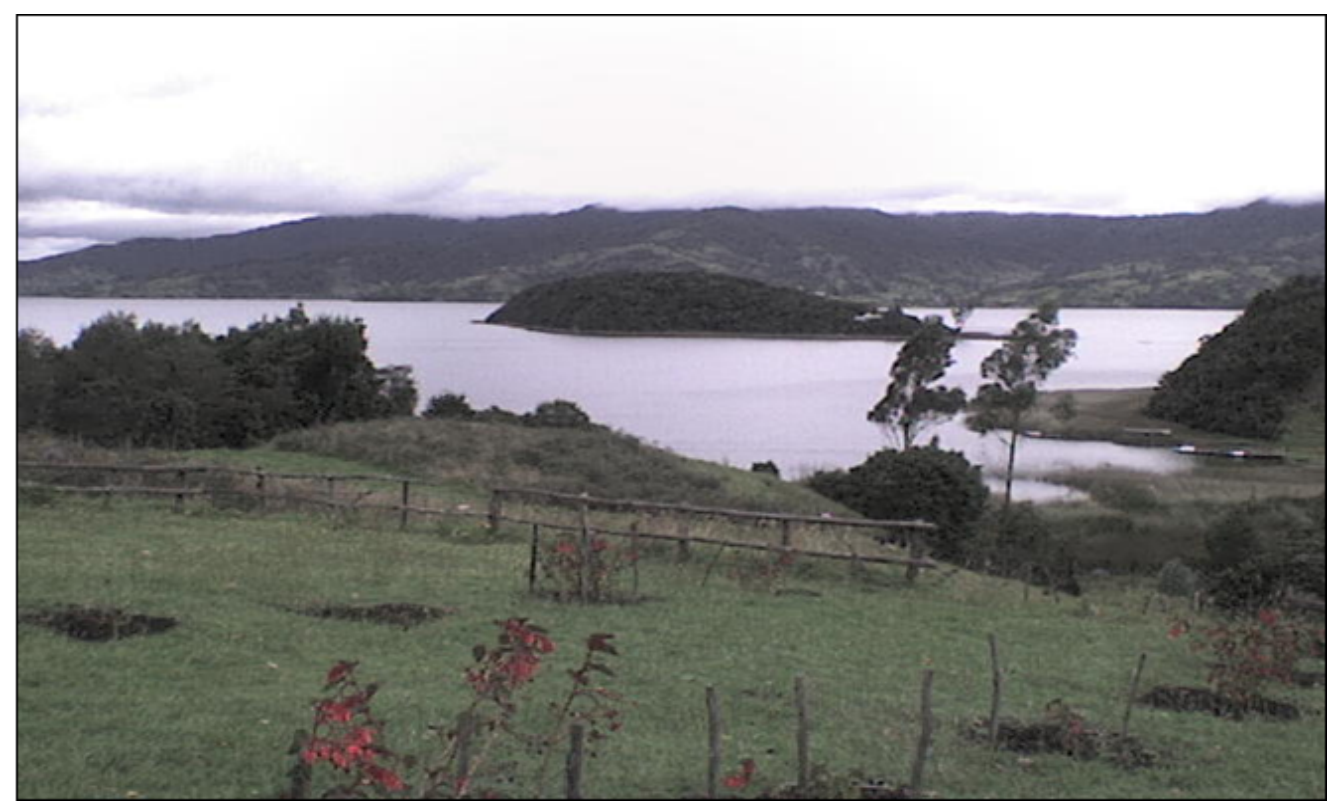

Figura 11. Laguna de la Cocha - Santuario de Flora y Fauna Isla La Corota. (Archivo personal de John de los Ríos).

Al respecto, el MMA, en la siguiente Providencia dispuso: Artículos $1^{\circ}, 4^{\circ}$, respectivamente: "No reponer el Auto No. 967 del 17 de diciembre de 2001 proferido por la subdirección de licencias ambientales del MMA; contra la presente providencia no procede recurso alguno por cuanto con la misma se agota la vía gubernativa" (Auto No. 467 del 9 de mayo de 1992 del MMA, p. 28).

Sin embargo, luego de estos antecedentes en la negación de la licencia ambiental al PMG, la sociedad económica influye para que en la gobernación de Nariño de Parmenio Cuéllar se presente un recurso de revocatoria directa a la decisión de negativa de licencia al PMG que enuncia en su parte final lo siguiente:

Los beneficios ambientales a nuestro juicio, son mayores que los probables impactos negativos, razón por la cual solicitamos respetuosamente al Ministerio, se permita presentar la información ambiental [necesaria] para completar el Diagnóstico Ambiental de alternativas y sobre esta nueva información se tomen las determinaciones pertinentes, dándole valor al contexto del desarrollo regional, que está necesaria y lógicamente ligado a este proyecto. ${ }^{32}$

Al igual, también desde Ecovida se tocan las puertas del gobernador Parmenio Cuéllar en la búsqueda de influir en las decisiones de la sociedad política regional: 
[...] con Parmenio Cuéllar, hice una vuelta, a él le habían presentado, pues la belleza, pues al igual que a todos. Y pues el doctor dijo que a él nunca nadie le había dicho que eso era así, que de lo contrario jamás hubiera apoyado eso. Y le mostré, en esas épocas salían unas revistas de Ecofondo [...] creo que es en una de esas revistas estaba, algo del PMG que nosotros habíamos escrito, en una de las primeras, donde, no sé si es la carta a Samper, bueno algo, de todas maneras Parmenio dijo, ay bueno y quiénes son esos del Ecofondo, y quiénes escribieron esto y tal, y le empezó una duda bien grande, juy!, sí eso fue buenísimo. (Entrevista con Leonor Martínez, 2008)

Hay otras organizaciones que también se ven movilizadas por la repercusión de este proceso a escribir al MMA como son los miembros del Cabildo Indígena, quienes manifiestan:

Queremos enfatizar que todos los Proyectos Nacionales y Regionales que puedan afectar a nuestras comunidades indígenas, deben ser consultados con nuestras autoridades tradicionales y en este orden cumplir la obligación constitucional y legal de respetar la identidad étnica y cultural de los pueblos indígenas. ${ }^{33}$

A la vez, los transportadores fluviales del Lago de la Cocha también hacen llegar sus querellas:

Con gran preocupación la empresa de transportadores fluviales del Putumayo Cootranspiñuña LTDA, con recorrido de Pto Asís, Piñuña Negro, Pto Ospina, Pto Leguizamo y el Encano [Nariño] y quienes transportamos mensualmente 4000 personas que tienen asentamiento en la cabecera del río Putumayo, solicitamos que este Ministerio se abstenga de expedir la licencia ambiental al Proyecto Multipropósito Guamués. ${ }^{34}$

Esta demanda específica de los transportadores es mencionada e incluida en los autos No. 067 del 17 de diciembre de 2001 y 467 del 9 de mayo de 2002, por tanto su petición directa es tenida en cuenta a la hora de tomar las decisiones de la negativa de licencia ambiental por parte del MMA al PMG.

Como hemos visto, la "política de influencia" del movimiento ambientalista de Pasto coloniza a la política local, regional y nacional en la búsqueda de su propósito de deslegitimar el PMG y de hacer que sus intereses prevalezcan en el espacio de la opinión pública. Primero a través del cruce de cartas con la administración Samper y el mensaje directo a su ministro de Medio Ambiente, el cual fue permeado por el movimiento; luego a las administraciones regionales para que ejercieran presión sobre Corponariño en aras de que asumiera su papel como autoridad ambiental frente al PMG; en lo local sobre el alcalde de Pasto, Antonio Navarro Wolf de la izquierda colombiana, respecto a este líder se demostró una vez más su falta de escucha o el interés por los requerimientos de los movimientos ambientalistas. Al igual en la consecución de esta investigación fue imposible conseguir las impresiones de Antonio Navarro, al igual que las del senador Parmenio Cuéllar del mismo partido político de la izquierda colombiana. "Aunque los movimientos verdes tienden frecuentemente a situarse en la izquierda, no existe ninguna afinidad evidente entre el ecologismo radical y el pensamiento de izquierda" (Giddens, 1996, p. 207). 


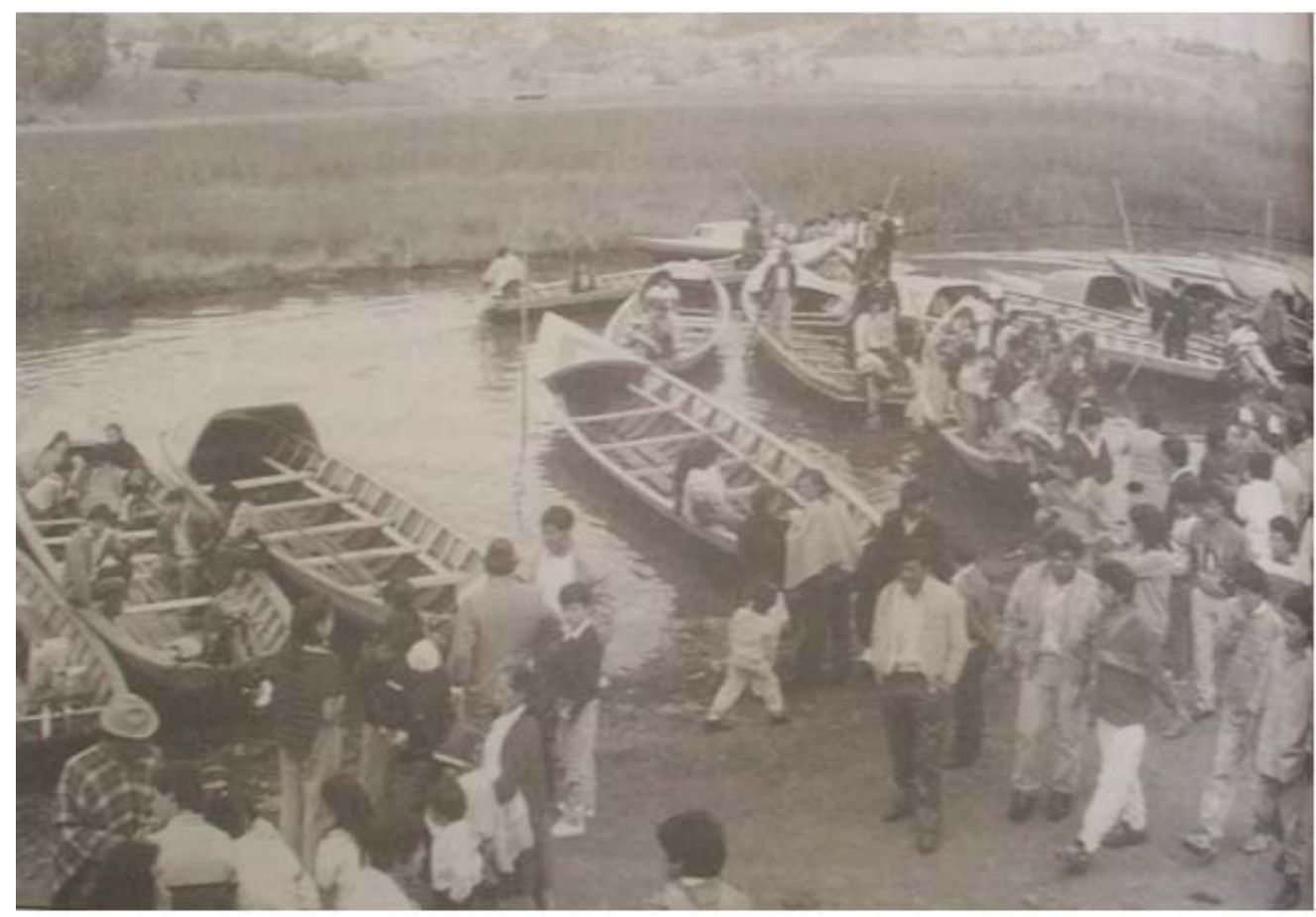

Figura 12. El Puerto, corregimiento del Encano (Pasto). (Diario del Sur, Pasto, 22 de abril de 1998, p. 6a).

El movimiento ambientalista local extendió sus redes a los transportadores fluviales, al recientemente fundado Cabildo Indígena del corregimiento del Encano, a las procuradurías regionales quienes también se pronunciaron ante el MMA.

A pesar de la distancia que existe entre Pasto y Bogotá capital Colombiana, donde se ubica la instancia del MMA, quien tomó la decisión sobre el PMG, el movimiento ambientalista local de Pasto mantuvo un comunicación fluida con dicho Ministerio y colonizó este espacio a su favor haciéndolo su aliado y moviéndolo a favor de sus intereses como la declaración del Lago de la Cocha como humedal Ramsar en el 2000 y en la reiterada negación de la licencia ambiental al PMG. Se evidencia que: "No obstante, la política de la influencia es el recurso por excelencia de los que carecen relativamente de poder, de los que se encuentran fuera de la política y de los que no tienen fuerza económica" (Cohen \& Arato, 2000, p. 569).

\section{Red en defensa de la Cocha}

La Fundación Ecovida y la Asociación para el Desarrollo Campesino -ADC- son las principales ONGA de Pasto que gestaron el proceso de movilización en defensa del Lago de la Cocha. Ecovida, una ONGA integrada por profesionales, surge de cuatro fuerzas principalmente: la primera, impregnada a partir del liderazgo de su fundadora y directora, Leonor Martínez; la segunda, a partir de la fundación de los grupos ecológicos en la UDENAR; la tercera, en razón de enlaces con el movimiento ambiental nacional en construcción; y la cuarta, de los contactos de líderes de grupos de la izquierda de Pasto. 
La ADC surge del encuentro de profesionales de Pasto y campesinos del Lago de la Cocha, más adelante obtiene ayuda de organismos de cooperación internacional y es colonizada por miembros del movimiento ambientalista nacional en construcción que transversalizan la temática ambiental en sus quehaceres.

Podemos evidenciar entonces en los integrantes de estas ONGA movilizadas por la temática ambientalista, su naturaleza plural, que se puede sintetizar a través de la descripción que Melucci retoma de Offe, veamos:

Su base social está localizada en tres sectores de la estructura social: 1) La "nueva clase media" o "clase de capital humano", es decir [...], las profesiones de servicios humanos y/o sector público (en especial, educación y asistencia), y quienes mantienen altos grados educativos y disfrutan de una relativa seguridad económica; 2) quienes ocupan una posición marginal respecto al mercado de trabajo (por ejemplo estudiantes, juventud desempleada [...]) y 3) elementos independientes de la "vieja clase media" (artesanos y granjeros, especialmente en las movilizaciones regionales y ambientales) [...] El grupo central de activistas y seguidores se encuentra en el primer grupo. (Offe, 1985 citado en Melucci, 2002, p. 71-72)

El encuentro de Ecovida y la ADC permite la extensión de sus redes generando solidaridad, que es parte de la "política de identidad" que despliegan los movimientos sociales. Las redes de Ecovida suman a la lucha en defensa del Lago del Cocha a estudiantes de la UDENAR, a la comunidad científica local y nacional, al Cabildo Indígena y a miembros de las autoridades locales, regionales y nacionales. Por su parte la ADC adhiere a la red, a la WWF, la Red de Reservas de la Sociedad Civil, Parques Nacionales, el Ministerio del Medio Ambiente. Se corrobora, entonces la noción de "campo ético político" en el análisis de los movimientos sociales contemporáneos:

En análisis recientes de acciones colectivas de movimientos sociales, tal noción ha sido vinculada con la emergencia de "redes" de movimientos sociales, con el fin de indicar la construcción colectiva que resulta de esta articulación de movimientos sociales de diferentes tipos con otros sectores y organizaciones, como partidos políticos, organizaciones de izquierda, la Iglesia católica, grupos científicos, organizaciones no gubernamentales (ONG), gremios, etc. (Dagnino, 2001, p. 70)

Al extender estas redes las ONGA buscan influir en la opinión pública para que sus demandas sean tenidas en cuenta. En este caso particular, fue a través del conocimiento experto como el movimiento ambientalista de Pasto, logró en primera instancia decretar al Lago de la Cocha como humedal Ramsar durante el periodo en el Ministerio del Ambiente de Juan Mayr Maldonado en el año 2000. El trabajo mancomunado de las redes (UDENAR, Parques Nacionales, Ecovida, ADC, WWF, Asdes, MMA, Corponariño) en el llenado de las ficha Ramsar y de una consulta previa a sus pobladores que se hizo soterradamente para evitar que la sociedad económica PMG se percatara de esta estrategia de los movilizados. Para este caso se prueba lo enunciado por Habermas (1998), el conocimiento experto se conectó retroalimentativamente con la formación democrática de la opinión, poniéndose a favor de los ciudadanos. 


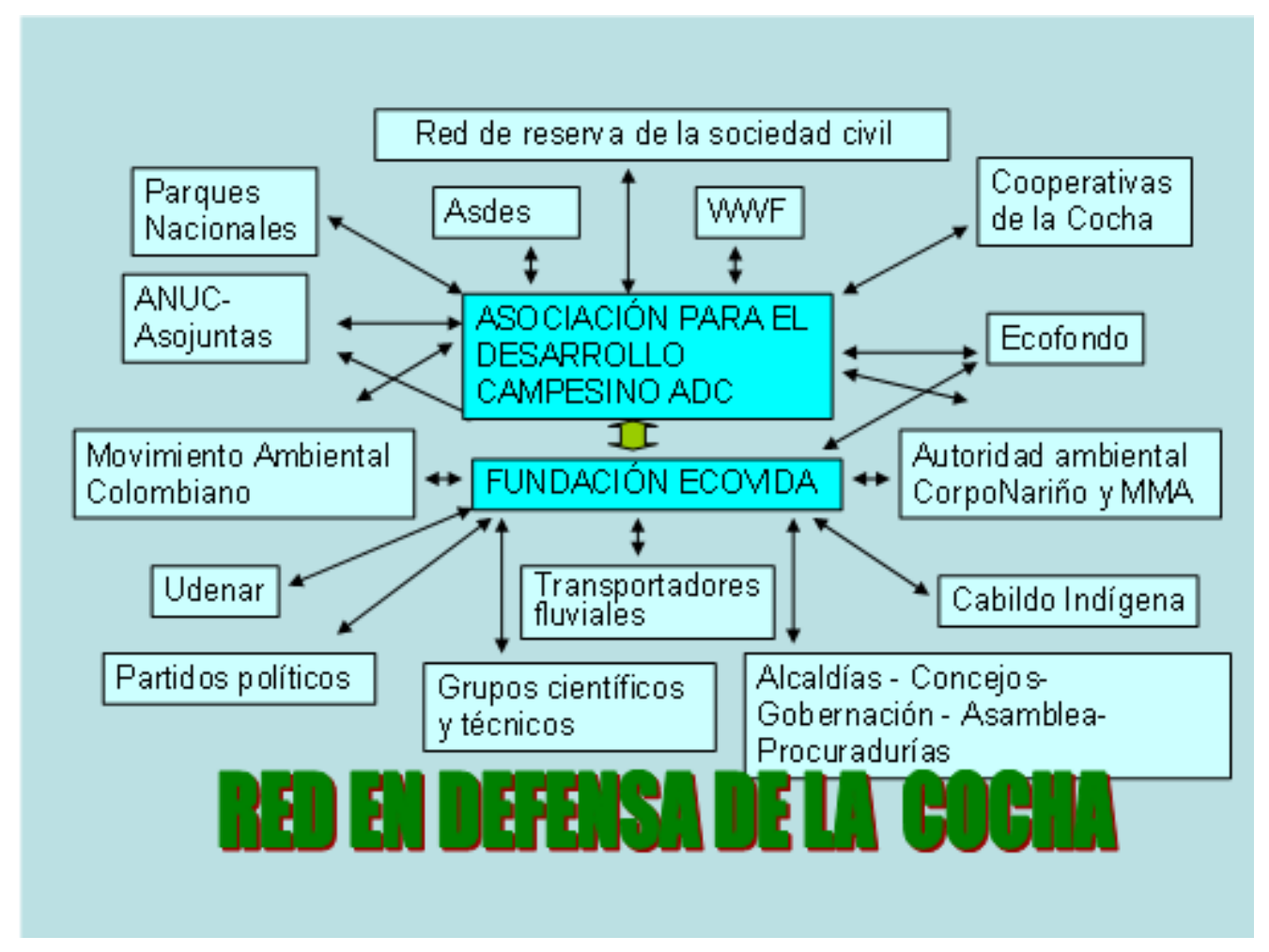

Figura 13. Red del movimiento en defensa del Lago de la Cocha

Con este triunfo de decretar a la Cocha humedal Ramsar, las diferentes organizaciones de la red continúan su "política de influencia" con más argumentos, ejerciendo persuasión y presión sobre diferentes partidos políticos, instituciones gubernamentales locales, regionales y del orden nacional especialmente del Ministerio del Medio Ambiente pregonando la inconveniencia de la licencia ambiental al PMG.

El departamento de Nariño en Colombia ha tenido una presencia fuerte de movimientos políticos de izquierda que accedieron democráticamente al poder y que alimentaron el recientemente creado partido Polo Democrático Alternativo. Los movimientos ambientalistas cifraron las esperanzas en que con el acceso democrático de estos grupos alternativos al poder sus demandas tendrían más receptividad, sin embargo, no fue así y dos de los líderes connotados de la región de Nariño que estuvieron en el poder se les percibió desde la mirada del movimiento ambientalista local como favorecedores e impulsores del PMG.

No obstante, hemos visto cómo los movimientos ambientalistas están más allá de izquierdas y derechas. Es por esto que para el caso de la resistencia al PMG la estrategia de la "política de influencia" fue igual para todos los matices políticos logrando, a través de la fuerza de las ideas argumentadas y sopesadas por el conocimiento experto, persuadir y colonizar a estos sectores en aras de obtener una negativa en el licenciamiento del PMG.

Toda esta movilización permitió que el Ministerio del Medio Ambiente negara la licencia ambiental al PMG según Auto No. 067 del 17 de diciembre de 2001, en dicho auto incluyó muchos de los temas debatidos en el Foro Científico, en los encuentros "Disoñadores" y en las exigencias sectoriales de organizaciones de la Red. Se constata una vez más con este estudio, de los movimientos 
ambientalistas en Colombia, algo que se ha evidenciado en otros países del mundo: "los ecologistas han recurrido al Estado para que ejerza presión sobre los actores económicos que saquean el ambiente" (Cohen \& Arato, 2000, p. 585).

\section{REFERENCIAS}

- Ángel Maya, A. (1997). Acariciando nuestros viejos fantasmas. En Se hace camino al andar. Aportes para una historia del Movimiento Ambiental en Colombia. Bogotá: Ecofondo.

- Álvarez, Sonia; Dagnino, Evelina y Escobar, Arturo. (2001). Introducción: Lo cultural y lo político en los movimientos sociales Latinoamericanos. En Política Cultural y Cultura Política. Bogotá: Taurus - ICANH.

- Álvarez Tamayo, Jairo H. (1997). Movimiento Ambiental Colombiano: como un pájaro Blanco Cegado por la Nieve. En Se hace camino al andar. Aportes para una historia del Movimiento Ambiental en Colombia. Bogotá: Ecofondo.

- Archila, Mauricio y Pardo, Mauricio. (2001). Movimientos sociales, Estado y Democracia en Colombia. Primera Edición. Bogotá: CES - Universidad Nacional de Colombia, ICANH.

- Asociación para el Desarrollo Campesino y Fundación Colombia Multicolor. (1997). Disoñadores del Futuro para Cambiar el Rumbo. Memorias. Pasto, Bogotá: ADC - Colombia Multicolor.

- Bustos, Germán. (1997). Tú me matas... Memoria de la casa Palermo. En Se hace camino al andar. Aportes para la historia del Movimiento Ambiental en Colombia. Bogotá: Ecofondo.

- Castro Matabanchoy, J. y Duque, Octavio. (1999). Pasto entre la sed y el agua. Pasto: Asociación para el Desarrollo Campesino.

- Cohen L., Jean y Arato, A. (2000). Sociedad civil y Teoría Política. México: Fondo de Cultura Económica.

- Dagnino Evelina (2001). Cultura, ciudadanía y democracia: Ios discursos y prácticas cambiantes de la izquierda latinoamericana. En Política Cultural y Cultura Política. Bogotá: Taurus - ICANH.

- Duque, Ana M. y Higging, Mary L. (1996, Agosto). WWF Frente a la Educación Ambiental. Boletín No. 17-18: 36. Ecofondo.

- Duque López, O. (1997). Una invitación a disoñar. En Disoñadores del Futuro para Cambiar el Rumbo. Memorias. Pasto, Bogotá: ACC Colombia Multicolor.

- Escobar, Arturo. (1999). El Final del Salvaje. Bogotá: CEREC- ICAN.

- Ecovida. Carta del 10 de octubre de 1994, firmada por 11 ONGA afiliadas a la Regional 7 de Ecofondo.

- $\quad$ El PMG, estado actual y problemas que generaría. Documento sin publicar.

- Giddens, Anthony. (1996). La modernidad bajo un signo negativo: cuestiones ecológicas y políticas de la vida. En Más allá de la Izquierda y la Derecha. Madrid: Cátedra.

- Habermas, Jürgen. (1998). Facticidad y Validez. Madrid: Editorial Trotta.

- (1987). Teoría de la Acción Comunicativa, I. Cuarta edición. Madrid: Taurus.

- Jojoa, Eusberto. (1997). Un sueño hecho realidad. En Disoñadores del Futuro para Cambiar el Rumbo. Memorias. Pasto, Bogotá: ACC Colombia Multicolor.

- López Arellano, J. (1993, Feb.). La Cocha. Características sociales y económicas de una región andina del sur de Colombia. Reporte de 
Investigación. Departamento de Antropología, Universidad Laval, Québec, Canadá.

- Martínez, Alier J. (2004). El ecologismo de los Pobres Conflictos ambientales y lenguajes de valoración. Barcelona: Icaria.

- Ménard, Renée. (1993, Abr.). Transferencia Tecnológica al femenino, los casos de Santa Lucía y Santa Isabel. Resumen de Investigación de Tesina. Departamento de Antropología, Universidad Laval, Québec, Canadá.

- Melucci, Alberto. (2002). Acción Colectiva, Vida cotidiana y Democracia. México: El Colegio de México.

- Ministerio del Ambiente, Vivienda y Desarrollo Territorial, Subdirección de Licencias Ambientales (1995). Expediente 509, Proyecto Multipropósito Guamúes. Carpetas 1 y 2.

- Palacin, Quispe M. (2008, Sep.). Experiencias y alternativas de los pueblos indígenas de América Latina frente a la Gran Minería. Conferencia presentada en el Foro Andino La Gran Minería. Bogotá.

- Palomino, Gonzalo. (1997). SOS Ecológico SOS. En Se hace camino al andar. Aportes para la historia del Movimiento Ambiental en Colombia. Bogotá: Ecofondo.

- Price Waterhouse Coopers. (1996). Informe Final PMG Proyecto Col 96/020.

- Sánchez, Luís E. (1995). Píldoras Ambientales. En Diario del Sur, junio 19, p. 6a. Pasto.

- Universidad de Nariño (edición). (1998). Memorias del Foro Científico. Video. San Juan de Pasto.

- . (1999). Reserva Natural camino del viento. Video. San Juan de Pasto.

- Uribe Hermosillo, Julio C. (2005). Las reservas como una opción. En Procesos de conservación, proceso de sistematización Ecofondo - ODA Canadá. Cartilla No. 1. Bogotá: Ecofondo.

- WWF (2002, 31 de julio de 2002). Herederos del Planeta. Extraído 15 de noviembre de 2008, desde http://ww.wwf.org.co/sala_redaccion/historias/?2630/Herederos-delplaneta.

\section{OTRAS FUENTES}

\section{Entrevistas}

- Cabrera, Jesús. Julio 2 de 2008, San Juan de Pasto.

- Fuentes, Ana M. Noviembre 26 de 2008, Bogotá.

- Insuasty Alvarado, E. Junio 27 de 2008, San Juan de Pasto.

- Martínez, Leonor. Junio 29 de 2008, San Juan de Pasto.

- Matabanchoy Concepción. Junio 30 de 2008, San Juan de Pasto.

- Mosquera, Yonny. Junio 28 de 2008, San Juan de Pasto.

- Villota Rafael. Julio 1 de 2008, San Juan de Pasto.

\section{Periódicos}

- Ayer en pasto Samper anunció apoyo al PMG. (1993, Nov. 13). Diario del Sur, p. 1 y $3 a$.

- Desde Planeación Nacional apoyo para la generación de energía desde la Cocha. (1992, Ago. 13). Diario del Sur, p. 1.

- Duque López, Octavio. (1996, Mar. 4). La Cocha, un humedal amenazado. Diario del Sur, p. 12a. 
- Gobierno Respalda el proyecto del Guamués. (1996, Nov. 26). Diario del Sur, p. 12a.

- Encuentro del Futuro en la Cocha. (1996, Jul. 15). Diario del Sur, p. 1 y 11 .

- Píldoras Ambientales. (1995, Jun. 19). Diario del Sur, p. $6 a$.

- Prendió Motores PMG. (1994, Jun. 22). Diario del Sur, p. 6a.

- Provisorio Porvenir con el Multipropósito Guamués. (1996, Oct. 12). Diario del Sur, p. 2a.

- Proyecto Multipropósito Guamués Comunidad Clave en el Diagnóstico. (1996, Nov. 26). Diario del Sur, p. 12a.

- \$1230 millones para Plan Proyecto Multipropósito. (1996, Nov. 11). Diario del Sur, p. 1 y 9 a.

\section{Fotografías}

- Archivo personal Jhon de los Ríos.

- Ariel Edmundo Tarazona Pedraza.

- Imágenes del Foro Científico.

- Periódico Diario del Sur.

1. Estudio cualitativo en el marco de la tesis de Maestría en Sociología de la Universidad Nacional de Colombia, titulada: "Lo Cultural y lo Político del Movimiento Ambientalista Colombiano a partir de 1990".

2. Sociólogo, Magíster en Sociología de la Universidad Nacional de Colombia sede Bogotá, integrante de la Línea de Investigación de Historia Ambiental de América Latina, que pertenece al grupo de Historia, Ambiente y Política de la Universidad Nacional de Colombia.

3. Octavio Duque López realizó estudios de filosofía y economía, fue cofundador de la ADC con su esposa Irma Quevedo. Actualmente, los esposos viven exiliados en Canadá, y fue imposible obtener su versión de esta movilización.

4. Convención Relativa a los Humedales de importancia Internacional especialmente como Hábitat de Aves Acuáticas, Irán, 2/2/1971. En Colombia se ratifica en el año 1997 como un instrumento de enorme importancia en la defensa de estos ecosistemas.

5. Leonor Martínez, Licenciada en Biología y Química, especialista en Ecología y Máster en Conservación y Gestión del Medio Natural. Profesora desde hace aprox. 30 años de la Universidad de Nariño UNDENAR-, es a la vez fundadora y directora de la Organización no Gubernamental ambientalista Ecovida.

6. Eusberto Jojoa Pardo, campesino enamorado y defensor del Lago de la Cocha y cofundador de la ADC, quien murió asesinado en enero de 2000 por grupos armados en inmediaciones del Lago de la Cocha.

7. En abril de 1992 se realizó la Asamblea General Ordinaria, en el municipio de Chachagüí, en Nariño, con el propósito de constituir formalmente la Asociación Red Colombiana de Reservas Naturales de la Sociedad Civil, donde se contó con la participación de 50 personas de 37 Reservas Naturales de todo el país. [Fuente: http://www.resnatut.opg.co/Quienessomos/historia (última consulta noviembre de 2008)].

8. Concepción Matabanchoy es una líder campesina, que fue "Mujer Cafam 2007", y heredó de su madre, doña Bertha Palacios (una de las pioneras de la Red de Reservas de la Sociedad Civil en la Cocha), el interés familiar por el cuidado de los bosques. 
9. Eybar Insuasty Alvarado, es profesional en Derecho, coordinador del área Gestión para el bien vivir local o área política de la ADC.

10. El arribó de Marie France Labrecque al departamento de Nariño es hacia 1988, con el fin de evaluar para la SDID los fondos entregados a los proyectos alternativos de producción campesina. En 1989 ya se concentra en investigación a través de la beca del Consejo de Investigación de Ciencias Humanas de Canadá y el Fondo FCAR del Ministerio de Educación Superior con la investigación titulada: "Desarrollo rural campesinado e integración de las mujeres al desarrollo: los casos de los departamentos de Nariño y Santander". El primer departamento fue asumido por su equipo de investigación, teniendo como auxiliar principal a José López Arellano, dando informes hacia 1993; entre uno de los resultados de esta investigación permitió que el Centro de Investigaciones para el Desarrollo, financiará un nuevo proyecto donde los campesinos se preparaban en pesquisas propias de las ciencias sociales, allí ya tomó el tinte de Investigación Acción Participación, controlada específicamente por miembros de las comunidades donde se trabaja.

11. "Para apropiarnos más de nuestro entorno usamos la minga investigativa como manera de acercarnos a la naturaleza para conocerla mejor y comprender lo que en ella sucede a partir de nuestra intervención en ella (entendimiento, afecto, identidad, creatividad). Algunas de las investigaciones: macrofauna del suelo, inventario de orquídeas, caracterización de la vegetación arbórea, propagación de clusia multiflora, anuros en áreas de conservación, comunidades aviarias en los páramos, distribución de espeletia cochensis, entre otras" (documento encontrado en los archivos de ADC, titulado: "Pasto un municipio entre la sed y el agua", de Octavio Duque López y Jaime Castro Matabanchoy, 1999).

12. "Identificar nuestras necesidades Fundamentales buscamos nuestros propios satisfactores, uno de ellos la protección de nuestro entorno natural, fue objeto de atención especial para nosotros; este satisfactor de nuestras necesidades básicas se concretizó en convertir nuestros predios en Reservas Naturales (áreas protegidas, que incluyen ecosistemas naturales, zonas productivas, zonas sociales y la familia misma); acogimos la iniciativa 52 familias que hoy protegemos los fragmentos de ecosistemas naturales, el agua y los suelos, en nuestras reservas (Satisfactor Sinérgico); en la Red José Gabriel protegemos 3000 hectáreas, 8\% del área de la cuenca alta del Guamués" (Documento encontrado en los archivos de ADC, titulado: "Pasto un municipio entre la sed y el agua", de Octavio Duque López y Jaime Castro Matabanchoy, 1999).

13. La sociedad PMG, o empresa de Servicios Públicos, surge como una alianza estratégica entre el sector público y el sector privado de Nariño. Según datos del ingeniero Francisco Arévalo, Gerente del PMG y promotor del mismo en aquel momento, aseguró haber invertido un capital privado de 150 millones de pesos en la sociedad PMG, que se entregaron a la empresa que hizo los primeros estudios de prefactibilidad (VideoMemorias del Foro Científico, UDENAR, 28 de noviembre de 1998, San Juan de Pasto). Por entrevista con el Sacerdote Rafael Villota (2008) miembro de la orden Jesuita, en San Juan de Pasto, aseveró cómo: las gestiones del padre Daniel Guerrero (miembro de esta misma orden), fallecido, y quien se destacó como férreo impulsor del PMG, llevaron a vincular algunos capitales de las instituciones educativas de la congregación Jesuita especialmente de Cali, en la sociedad PMG. Al igual en entrevista con Jesús Cabrera (2008), planificador del Desarrollo y miembro de la sociedad PMG en San Juan de Pasto, dijo haber invertido dineros personales en dicha sociedad que se vieron en riesgo. A la vez el padre Daniel Guerrero bajo una sugestiva campaña en los medios de 
comunicación persuadió a las administraciones de municipios de Nariño a invertir acciones en la sociedad PMG.

14. En carta del 19 de noviembre de 1996 dirigida al Gerente del PMG y al MMA por parte del Comité Ejecutivo Sindepeagronar Fensuagro - CUT seccional Nariño Colombia, en su punto inicial aduce que debido al elevado precio de las tarifas de energía en el departamento de Nariño, "le suplicamos señor ministro la necesidad de adelantar y dar vía lo más rápido posible a la empresa PMG". Al igual se anexa a esta carta, un acta de reunión del 15 de septiembre de 1996 de este mismo sindicato, que en su punto 14 menciona: "Rechazo a los falsos representantes ante el Consejo de Corponariño como son las organizaciones ADC y otras" (expediente No. 509 de licencias ambientales del MAVDT, folios: 162, 163, $164,165)$. Lo que hace falta comprender de esta fisura entre organizaciones es si ella se origina en una colonización de la sociedad económica PMG hacia la sociedad civil para tratar de escindir la lucha. Hay que recordar que la sociedad PMG como estrategia para ganar base social, adelantó proyectos productivos, en las veredas aledañas a la Cocha (al respecto de esto último, ver Diario el Sur, San Juan de Pasto, 12 de octubre de 1996, p. 2a).

15. Yonny Mosquera en aquel momento era estudiante participe del Grupo "Amigos de la Cocha", hoy ya se graduó como profesional en Geografía, aficionado a la producción de video y continúa como activista de causas ambientales.

16. De este evento se debe destacar la participación de los Drs. Luís Eduardo Mora Osejo premio Nacional de la Ciencia y Presidente ACCCEFN, Tomas Vander Hammen científico Holandés de la Universidad de Amsterdam y residente en Colombia en ese entonces. A nivel local presentaron sus ponencias relacionadas con el PMG las investigadoras: María Elena Solarte y Marta Sofía González, quienes en ese mismo año lograron el premio Nacional que otorga la Asociación Colombiana de Ciencias Biológicas A.C.C.B. por su investigación sobre la Espeletia cochensis (variedad de frailejón), como especie endémica que desaparecería en el supuesto caso de hacerse el PMG. También participó el Dr. Edgar Abraham Cabrera del Dpto. de física y el estudiante Yonny Mosquera del Departamento de Geografía y del Grupo Ecológico "Amigos de la Cocha". Este último calculó las áreas de inundación del PMG (fuente: documento del archivo de Ecovida, titulado: "El PMG, estado actual y problemas que generaría").

17. Por referencia del Diario el Sur de pasto del 15 de julio de 1996, en la página primera y $11 \mathrm{a}$, se comenta del "Encuentro del Futuro en la Cocha" para el 22 y 25 de julio de 1996. El lanzamiento del encuentro se hizo en el auditorio Planetario Distrital de Bogotá el 12 de julio de 1996; y en rueda de prensa se dio a conocer el propósito del certamen, allí se menciona que harán presencia el grupo de niños, Herederos del Planeta, que fueron galardonados con el premio Global 500 de medio ambiente de las Naciones Unidas, además entre otros, Gloria Cuartas alcaldesa de Apartadó, y el alcalde de Pasto Antonio Navarro Wolf, el siquiatra Luís Carlos Restrepo y la antropóloga de la Universidad Laval de Québec, Marie France Labrecque.

18. Octavio Duque, Mario Calderón, Augusto Ángel, Gustavo Wilches Chaux, León Octavio Osorno.

19. En el año de 1993 se da como un nuevo proceso en Colombia de la WWF, que ellos denominan la consolidación de una oficina de programa (http://www.wwf.org.co/co/about_us/) y que la prensa Colombiana registra como: "La prestigiosa organización ambientalista internacional Fondo Mundial para la Naturaleza (WWF) comenzó a funcionar este año en Colombia. La WWF cuyo logo el Oso Panda es famoso en los cinco 
continentes, montó su base de operaciones colombiana en la ciudad de Cali, apoyada por la Fundación FES" (Vanguardia Liberal, 18 de mayo de 1994, p. Ola Verde).

20. Documento de la WWF hallado en el archivo de la ADC sobre reunión realizada el 17 de julio de 1997 entre Fabio Londoño de Asdes y Mary Lou Higgins, Susana Pimiento de la WWF, en referencia al Proyecto Multipropósito Guamués.

21. Ana María Fuentes es Ingeniera Agrónoma, quien laboró en la ADC desde 1999 en el área de Soberanía Alimentaría y Conservación de la Biodiversidad y fue directora de ADC entre 2003-2004, hoy se desempeña como funcionaria de Parques Nacionales en Bogotá D.C.

22. Apartes de la carta enviada al presidente Ernesto Samper Pizano el 10 de Octubre de 1994, firmada por 11 ONGA afiliadas a la Regional 7 de Ecofondo, la Parroquia del Encano (Diócesis de Pasto), Juntas de Acción Comunal de la Cocha, la Asociación de mujeres, el Mercado comentario Campesino, el Restaurante Viracocha, y 19 firmas más de particulares (Archivo Ecovida, San Juan de Pasto).

23. Antonio Navarro Wolf se posesionó como alcalde de Pasto en 1995 y hubo muchas cercanías entre la administración central y la local; en el tema anecdótico hay que recordar cómo Samper Pizano fue padrino de matrimonio de Navarro Wolf.

24. Reiteradamente se menciona la incidencia de Corponariño como interesada en la participación y ejecución del PMG, y además competía con otras entidades locales y nacionales por formar parte como inversionista del proyecto, lo que trajo colisiones interinstitucionales (ver al respecto: Diario del Sur, San Juan de pasto, 13 de agosto de 1992, p. primera; 22 de junio de 1994, p. 6a local; 11 de noviembre de 1996, p. primera y 9 a).

25. En carta de noviembre 24 de 1996 respaldada por 68 firmas de los ambientalistas de Pasto le comentan a José Vicente Mogollón, Ministro del Medio Ambiente, sus molestias por el apoyo de varias instituciones al PMG. En el punto tercero de la misma comentan: "Por otro lado, mientras la Ley 99 exige que se escuche a las comunidades, y que se explique los impactos ambientales y sociales, nuestras instituciones ambientales, municipal, departamental y Corponariño en particular que deberían estar en la defensa de la Cocha son la impulsoras de este proyecto, y jamás han procurado cumplir con su misión de enseñarle a los campesinos sobre la gravedad de la situación ni en mejorar la calidad de vida de ellos" (Archivo de licencias ambientales del MAVDT, folio 149, Expediente 509).

26. Carta fechada del 20 de octubre de 1994 en San Juan de Pasto, dirigida a Ana Victoria Apraez, Directora ejecutiva de Corponariño, firmada por el gobernador de Nariño, Álvaro Zarama Medina y el alcalde de Pasto Eduardo Romo Rosero (Expediente 509 de licencias ambientales del Ministerio del Medio Ambiente, vivienda y Desarrollo Territorial, carpeta 1, folio 1).

27. Apartes de la carta dirigida a Eduardo Verano de La Rosa el 20 de marzo de 1997 y firmada por Concepción Matabanchoy de la Organización Comunitaria para el Desarrollo -OCD- (Expediente 509 de licencias ambientales del MAVDT, carpeta 1, folio 166).

28. El Concejo Municipal de Pasto en el Acuerdo No. 152 del 13 de octubre de 1994 en su Artículo 1, le autoriza al alcalde municipal para tramitar recursos de financiación con FONADE por la suma de 15'000.000; Artículo 2, los recursos de financiación se destinarán para contratar la consultoría para los estudios del proyecto PMG. El Contrato de consultoría No. 671 de 1994 celebrado entre el departamento de Nariño y la sociedad "Hídrica Ltda.", firmado por Fabio Calvache Santander, gobernador y Francisco 
Arévalo Castellanos el contratista (Expediente de licencias del MAVDT No. 509 , carpeta 1 , folios $57,58,59,60,64)$.

29. Martínez Alier (2004) al respecto comenta: "En las democracias, a los políticos del pasado reciente les gustaba basar sus decisiones en la ciencia confiable, y escoger de manera racional la opción óptima. No las grandes represas a cualquier costo pero sí las grandes represas después del análisis costo-beneficio con todas las externalidades incluidas. A veces frente a las incertidumbres y las urgencias, los Estados ahora se están distanciando de una estrategia de legitimación de la toma de decisiones en la cual la ciencia servía a la política, hacia otra estrategia diferente, una llamada hacia la gobernanza o gobernabilidad, definida, como la capacidad de aprovechar una amplia gama de opiniones de expertos y sectores afectados, para que las decisiones sean mejor informadas y descansen sobre una base amplia de consenso. En vez de soluciones óptimas, aceptemos soluciones acordadas. Los lenguajes de valoración son más diversos. El Estado se vuelve más permeable" (p. 256).

30. Se registran dos cartas de la Procuraduría Judicial Ambiental y Agraria de Nariño y Putumayo dirigidas al MMA, del 28 de mayo y del 9 de septiembre de 1998, respectivamente, solicitando información específica por las gestiones del PMG (Expediente de licencias No. 509 del MAVDT, carpeta 1, folios 192, 193).

31. Carta de la Procuraduría Judicial Ambiental y Agraria de Nariño y Putumayo del 6 de febrero de 2001 dirigida al MMA (Expediente de licencias No. 509 del MAVDT, carpeta 2, folio 225).

32. Carta dirigida a la Ministra del MMA, Cecilia Rodríguez, del 11 de septiembre de 2002, firmada por la gerente del PMG, Leonor Moreno Mesías, el Gobernador de Nariño, Parmenio Cuéllar y el alcalde de Pasto, Eduardo Alvarado S. (Expediente 509 del MAVDT, folios 459-460).

33. Carta dirigida al Ministro del Medio Ambiente Juan Mayr Maldonado el 21 de julio de 2001, por Segundo Benavides Mavisoy (asesinado) Gobernador del Resguardo Indígena Quillasinga "Refugio del Sol" (Expediente de licencias ambientales No. 509 del MAVDT).

34. Carta dirigida al Ministro del Medio Ambiente el 15 de abril de 1991 por parte de Luís Jorge Salazar, gerente de Cootranspiñuña LTDA. (Expediente de licencias ambientales No. 509 del MAVDT). 